\title{
An Assessment of Supply Chain Disruption Mitigation Strategies
}

\section{ABSTRACT}

We assess the effectiveness of incorporating three types of redundancy practices(pre-positioning inventory, backup suppliers, and protected suppliers) intoa firm's supply chainthat isexposed to two types of risk: supply risk and environmental risk. Supply risk disrupts an individual supplier, while environmental risk makes a number of suppliers in a given region unavailable.An additional factor is supplier interdependence,where a disruption in one supplier may also disrupt other active suppliers. Utilizing the concept of a decision tree to capture different disruption scenarios, we develop a two-stage mixed-integer programming (two-stage MIP) model as a General Model to address the problem of supplier selection and order allocationunder supplier dependencies and risk of disruptions.In the General Model, multi-sourcing is the only supplier strategy that the firm implements. Then we develop three separate extensions of theGeneral Model,one foreach of the three redundancy practices, and evaluate the expected supply chain costof each extended model. We quantitatively show how adding redundancy to the supply chain in different forms, along with contingency plans, can help firms mitigate the impact of supply chain disruptions.The findings suggest thatall three strategies reduce costs and risks compared to the General Model. An analysis of reliability, risks, dependence, and costs is conducted on each strategy to provide insights into supplier selection, demand allocation, and capability development in a supply chain under supply chain risks.Finally, we show that regionalizinga supply chain is an effective way to mitigate the negative impacts ofenvironmental disruptionson the supply chain.

Keywords: Supply Risk, Environmental Risk, Pre-positioning Inventory, Backup Supplier,Protected Supplier, Redundancy, Two-Stage Mixed Integer Programming

\section{Introduction}

Supplier selection and demand allocation play key roles in the strategic success of a firm'sattemptsto meet customer demand, and in support of the firm's long-term strategy and competitiveness (Mendoza and Ventura, 2012). Supplier selection can reduce operational costs, improve product quality, reduce time-to-market, and increase supply-chain efficiency (Che and Wang, 2008). Trends such as globalization and increasing international tradehave motivated firms to extend their supply chains across the globe to get access to new markets, reduce their production cost, and enhance their competitiveness. As a result of the increased complexity of supply chains, firms have become more vulnerable to supply chain disruptions, because in a global supply chain, a firm's performance is more dependent on the actions and performance of its extended supply chain network(Ghadge et al., 2013; Bode and Wagner, 2015; Paul et al., 2015).Roberta Pereira et al. (2014) highlightedthe upstream of a supply chain as the most critical point in a supply chain exposed to disruptions. Thus, sourcing and procurement decisions have become critical business activities. 
According to Bode and Wagner (2015), supply chain disruption is defined as the combination of an unintended and unexpected triggering event that occurs somewhere in the upstream supply chain, the inbound logistics network, or the purchasing (sourcing) environment, and the consequent situation that presents a serious threat to the normal course of business operations of the focal firm. Because of their concern regarding supply chain disruptions, many firms have showed increased interest in incorporating disruption risks into their purchasing and sourcing strategies, and supply chain risk management (SCRM) has received significant attention (Sodhi et al., 2012; Chopra and Sodhi, 2014). SCRM is the implementation of strategies to manage risks along the supply chain based on continuous risk assessment, with the objective of reducing vulnerability and ensuring continuity (Wieland and Wallenburg, 2012).

Bradley (2014) suggested a five step method for SCRM: 1) identify risks, 2) measure risks, 3) prioritize risks for mitigation, 4) evaluate risk mitigation tactics, and 5) implement risk mitigation tactics. He then explored the first three steps, naming them as the foundation for evaluating and implementing mitigation tactics. With respect to the risk identification step, suppliers and locations are considered two physical aspects of a generic supply chain where disruptions may threaten the normal flow of goods from upstream.Supplier disruptions are due to flaws and problems in suppliers' operations. The Boeing Dreamliner program lost nearly $\$ 2.5$ billion cash-flow due to a shortage of bolts and screws arising from a disruption at one of their smallest suppliers (Greising and Johnsson, 2007).Suppliers do not operate in isolation. According to Wagner et al. (2009), empirical research has found positive correlations between firms' disruptions, which means a disruption in one supplier may also disrupt another supplier. The location category describes events that affect an entire geographical area, such as natural disasters and sociopolitical unrest. This type of disruption, which we call environmental disruption in this paper from now on, disrupts a number of suppliers at the same time, and the detrimental impact is more destructive and may remain in place for a longer period of time. The Japanese tsunami in 2011, Thailand's flood in 2011, and the 2010 eruption of a volcano in Iceland respectively disrupted the auto industry, the computer industry, and millions of air travelers and air shipments(Chen and Wu, 2013; Chopra and Sodhi, 2014). Recent surveys of practitioners and academics have underlined the importance of SCRM as well as the need for more empirical and analytical studies in this area (Zsidisin and Wagner, 2010; Ghadge et al., 2013; Kamalahmadi and Mellat-Parast, 2016a).

In this study, we extend Bradley (2014)'s study to cover the last two steps, evaluating and implementing risk mitigation tactics, and to address the call for new analytical research in this area.We consider three reasons for suppliers' unavailability: 1) an environmental disruption, which makes a number of suppliers in the same location unavailable; 2) a supplier disruption,which disrupts a single supplier; and 3) disruption dependence or unavailability of a supplier, because of a disruption in another supplier. We then analyze the tradeoff between costs and risksof using different mitigation tactics 
todesign a supply chain resilient andresponsive to supplier and environmental disruptions. We examine the effectiveness of adding three types of redundancies (inventory, backup suppliers, and protected suppliers) to the supply chain and suggest contingency plans to help implement each of the strategies.Our study is unique in that we examine the effectiveness of three mitigation tactics against two types of disruptionsin the upstream of a supply chain,we take into account suppliers' disruption dependenceor independence, and we show howimplementation of redundancy practices can improve a firm's performance in a turbulent and complex business environment.

The remainder of this paper is organized as follows. In section two, we provide an overview of the related literature and explain why we have chosen the three particular sourcing strategies in this study. In section three, we develop our SCRM model to examine the tradeoff between costs and risks as well as the responsivenessof different supply-disruption mitigation strategiesto supplier and environmental disruptions. In section four, we show a computational example of our model, and discuss application of the strategies quantitatively. In section five, we evaluate the results of the computational example, and conduct two sensitivity analyses to examine how each type of disruption can affect the results. Finally, in section six, we discuss the theoretical contributions, managerial implications, and limitations of our study.

\section{Literature Review}

We present the literature related to this study in several subsections. We first review some of the studies that incorporated SCRM into sourcing decisions and explain why we have chosen these three sourcing strategies: inventory, backup suppliers, and protected suppliers. Then we discuss the related literature on each strategy. Finally, we explain how our study contributes to the SCRM literature.

\subsection{Integration of SCRM and sourcing strategies}

This study is concerned with the literature on incorporating supplier and environmental disruptions into sourcing decisions. This topic was initially examined by Berger et al. (2004), where they defined three types of disruption: a unique event (disruption in a single supplier);a semi-super event (simultaneous disruptions in more than one supplier); and a super event (an event that affects all suppliers). Ignoring semi-super events, they developed a simple model to discuss the financial losses that the other two types can cause. Berger and Zeng (2006) relaxed some of the assumptions such as equal failure probabilities for unique events and found the optimal number of suppliers with their new assumptions. Their model was extended by Ruiz-Torres andMahmoodi (2007) when they added a partial loss associated with the failure of any individual supplier to the model and discussedits effect in situations where suppliers have equal or unequal failure probabilities. Meena et al. (2011) considered minimization of costs and maximization of service level and designed an algorithm to find the optimal size of the supply base under disruptions.Meena and Sarmah (2013) proposed a mixed-integernon-linear 
programming model for order allocation considering different capacities, failure probabilities, and quantitydiscounts for each supplier.

There are only a few studies that examined environmental disruptions. Sarkar and Mohapatra (2009) added semi-super events to the supplier selection problem and used a tabular method to find the optimal size of the supply base. Sawik (2014) considered single and multiple sourcing strategiesin the presence of supplier, regional, and global disruptionsand developed an MIP modelwith conditional value at risk as a risk measure, with the objective of either minimizing expected worst-case loss ormaximizing expected worst-case service level.Finally, Kamalahmadi and Mellat-Parast (2016b) studied the supplier selection and demand allocation problem under supplier and regional disruptions, considering the flexibility in suppliers' capacities, and provided insights on how to use flexible capacity of suppliers to minimize disruption effects.

Disruption dependence is also a topic that has not received much attention. There are only two related studies that took disruption dependence into consideration.Babich et al. (2007) considered a competition between risky suppliers for a retailer's business and studied the relationship between wholesale price and order quantity of suppliers, taking into account demand uncertainty and suppliers' disruption and dependence. Their findings demonstrated that it is necessary to include disruption dependence in operational planning decisions. In another study, Wagner et al. (2009) used empirical data from the automotive industry to show disruption dependence exists and can have significant consequences.

This study belongs toa second stream of the literature, whichis concerned with the costs and benefits of different disruption management strategies. Many studies have discussed different practices that can be incorporated into sourcing decisions to improve the resiliency and responsiveness of a supply chain, mainly focusing on adding redundancy or flexibility to the supply chain (Kamalahmadi and MellatParast, 2016a). This classification was neatly presented by Tomlin (2006) where he categorized disruption strategies into two groups based on tactics: mitigation tactics, in whicha firm takes action in advance of disruptions and incurs the cost of the action regardless of whether a disruption occurs; and contingent tactics, wherea firm takes action only when disruption happens and avoids any pre-investment on any sort of redundancy. Our review of the literature suggests that flexibility has received more attention compared to redundancy, in recent years (Tomlin, 2006; Ruiz-Torres and Mahmoodi, 2006; Ruiz-Torres et al., 2013, Kamalahmadi and Mellat-Parast, 2016b). One reason might be that adding redundancy adds more costs, which could have a negative impact on supply chain cost efficiency (Chopra and Sodhi, 2014). Thus, our study is concerned with redundancy strategies that are concerned with improving supply chain responsiveness. To do so, we consider three types of redundancy that require pre-disruption investment:inventory, backup suppliers, and protected suppliers. 


\subsubsection{Pre-positioning inventory}

Toyota Motor North America announced in 2009 that they warehouse key parts to safeguard against supply chain disruptions caused by supplier failure (Chappell and Sedgwick, 2009). Increasing inventory or emergency supplies (also called operational slack) is defined as keeping buffer stocks of raw materials or finished goods (Sheffi, 2005). Pre-positioning inventory is usually classified as a redundant strategy that can act as a double-edged sword. Although it can buffer against supply disruptions and ensure production continuity, excess inventory is costly. It can increase cost, reduce quality, and reduce profitability. In fact, pre-positioning inventory challenges some existing management practices such as lean and JIT (Irvine, 2003; Sheffi, 2005; Obermaier, 2012; Azadegan et al., 2013). Excess inventory is mostly recommended for items that have low holding cost and are not perishable (Wilson, 2007). In this study, we assume that this type of inventory must be kept at pre-positioning warehouses. An example of the application of this strategy was when Playmate Toys mitigated the impact of a 2002 West-Coast disruption by investing in inventory earlier in the year (Tomlin, 2006).

As we mentioned,pre-positioning inventory is also called operational slack. Azadegan et al. (2013) defined operational slack as temporal, labor, or physical excesses in production processes. They investigated the impact of operational slack on a firm's survival when the firm is exposed to environmental risk. Their results indicated that operational slack would reduce the likelihood of failure in an environment with high uncertainty. Hendricks et al. (2009) empirically examined the influence of operational slack on stock market reaction to supply chain disruptions. Based on a sample of 307 disruptions announced in supply chains during 1987-1998, their analysis showed that firms with more slack in their supply chains experienced less negative stock market reaction after disruptions.

There is also a growing body of literature about pre-positioning inventory in disaster management. An example is Rawls and Turnquist (2010) who developed a two-stage stochastic mixedinteger program (SMIP) that uses a pre-positioning strategy to provide an emergency response to the threat of a hurricaneor other disasters. Due to the complexity of the model, they used a heuristic algorithm, the Lagrangian L-shaped method (LLSM), to determine the optimal decision.

\subsubsection{Backup suppliers}

A backup supplier is a secondary supplier that is used only when a primary supplier is disrupted. Contracting with a backup supplier ensures that the flow of material is maintained if disruption happens in other sources (Tomlin, 2006; Sodhi and Lee, 2007). Since the firm makes the contract prior to any disruption, this strategy is classified as a mitigation tactic. However, in contrast with pre-positioning inventory, it is not the firm that keeps the inventory. Rather, the supplier holds inventories in their warehouses.In addition, compared to a multi-sourcing strategy, in which all suppliers are used as primary sources of materials, backup suppliers are only used with primary suppliers are unavailable. 
Previous studies in backup supplier strategies underline the importance of this mitigation strategy in supply chain risk management. Hou et al. (2010) studied a buy-back contract between a buyer and a backup supplier when the main supplier experiences disruption. Using an expected profit function, the optimal decisions of the contract players are derived through a sequential optimization process. Chen et al. (2012) considered a periodic review inventory system with an unreliable supplier that may be disrupted and a backup supplier (with higher prices and limited capacity) that can be used during disruption. They developed a mathematical model in order to find the optimal order policy in the designed environment.Rafiei et al. (2013) considered a multi-segment multi-product, multi-period supply chain network with primary and backup suppliers in which reserved capacity in backup suppliers is used to respond to disruptions. They developed a priority-based genetic algorithm to solve the model and provide insights on supply chain design. Finally, Torabi et al. (2015) proposed a bi-objective mixed-probabilistic two-stage stochastic programming model and took into account contracting with backup suppliers. They proposed a 5-step process to solve for the optimal supplier selection and allocation for disruption management capacity.

\subsubsection{Protected suppliers}

In the wake of the Rana Plaza building collapse in Bangladesh that killed 1,100 workers, many global retailers sourcing from suppliers using that building agreed to spend hundreds of millions of dollars to fund fire-safety and structural improvement in the factories of their Bangladeshi suppliers (Greenhouse, 2013). Protecting suppliers is a strategy to fortify suppliers in order to strengthen their reliability and resiliency during disruptions and in turbulent environments (Sawik, 2013). Another example of protected suppliers is a flood wall in Bangkok, Thailand, being constructed around the perimeter of an industrial zone in which over 200 factories of electronics and computer components suppliers were located before a 2011 flood (Fuller, 2012).This strategy is concerned with identifying optimal sourcing policies for supplier selection and resource allocation, based on protected suppliers. Sawik (2013) examined the selection of suppliers to be protected against disruption, and developed mechanisms for the allocation of emergency inventory of parts to be pre-positioned at the protected suppliers. He determined the optimal selection and allocation of protected and unprotected suppliers in order to minimize the total cost. Qin et al. (2013) incorporated both facility protection and emergency inventory pre-positioning into a fortification model that identified the optimal allocation of a limited budget for protection investment in an existing capacitated logistics system in order to cope with random facility disruptions. They used two-stage stochastic mixed-integer programming and developed a revised disjunctive decomposition-based branch-and-cut (D2-BAC) algorithm to find the optimal strategy. Their empirical results determine the optimal value of a protection budget, and show that after they surpass this threshold, the marginal improvement from additional protection resources is negligible. Finally, Torabi et 
al. (2015) extended the Sawik (2013) paper by assuming that the fortification of a supplier decreases the impact of disruptions on that supplier, based on the level of protection and the disruption event. They developed a model allowing a mixture of protected suppliers and backup suppliers and solved it using a 5step process.

\subsection{Contributions of this study to SCRM}

Our study extends previous research in supply disruption and resource allocation. Following the methodology proposed by Ruiz-Torres et al. (2013), using a decision-tree analysis, we first design an algorithm to find the likelihood ofall scenarios that may happen as the result of failures in suppliers (supplier disruptions) and regions (environmental disruptions); then, using a two-stage mixed-integer programming model, we determine the optimal supplier selection and resource allocation, as well as selection and allocation of disruption mitigation resources.

Our study makes two important contributions to supply chain risk management literature. First, in order to examine the impact of adding redundancy and incorporating disruption mitigation strategies, we develop sourcing strategies based on the three types of redundanciesusing a two-stage mixed-integer programming model. Supplier selection and allocation are decisions made prior to acquiring knowledge of any specific disruption;in order to properly capture the stochastic nature of the problem, two-stage mixed-integer programming models are selected to represent the stochastic environment well. This approach to modeling supply chain disruptions has been used in previous studies in disruption and disaster management in order to evaluate pre- and post-disruption decisions ( $\mathrm{Li}$ et al., 2008; Xu and Nozick, 2009; Rawls and Turnquist, 2010; Guericke et al., 2012; Qin et al., 2013). The two-stage mixedinteger programming model incorporates the risk of disruption by assigning probabilities for each scenario due to supply failure (supplier disruptions) or regional failure (environmental disruptions). The model provides insight for supplierselection and allocationdecisions and for the firm's development of contingency plans using redundant resources, in order to satisfy customer demand in both normal and disruption conditions. To the best of our knowledge, it is one of the first studies that examines the impact of different disruption mitigation strategies in sourcing activities, particularly supplier selection and demand allocation decisions. Second, by considering two types of disruptions (supplier and environmental), we extend SCRM literature by incorporating both supplier and environmental risk into a supply chain risk management model with respect to three risk management mitigation strategies (prepositioning inventory, backup suppliers, and protected suppliers). Our conceptualization and operationalization of supply chain risk management suggest that a firm should baseits risk mitigation strategies not only on suppliers' capabilities, but also on the risk in the business environment. More specifically, in the Pre-positioning Inventory Model, warehouses are exposed to regional disruptions; in the Backup Suppliers Model, backup suppliers are not only exposed to regional disruptions, they may also 
experience supplier disruptions; intheProtectedSuppliers Model, the focal firm can choose which suppliers it wants to protect; but this protection is limited to supplier disruptions, and the protected suppliers are still exposed to regional disruptions. Thus, our approach to supply chain risk management provides a more nuanced explanation of the mitigation strategies a firm can implement in order to be more responsive to supply chain disruption, incorporating both supplier and environmental risks.

In addition, our model includessuppliers' dependenceon one another in case of individual disruptions, and our model uses a regionalized setting in which suppliers are located in different regions and environmental disruption is region-specific.This makes our model a more realistic supply chain in which 1) disruption in one supplier impacts other suppliers in the same industry as well, and 2) an environmentally initiated disaster may disrupt a number of suppliers that are located near each other.We also examine thevalidity of the strategy of regionalizing suggested by Chopra and Sodhi (2014) as a means to reduce environmental risks and disruptions.

\section{Model Descriptions}

In this section, the problems and the models are presented. We divide the rest of this section into four parts to emphasize the differences among our models. In the first section, we explain the general problem of supplier selection and demand allocation under supply and environmental disruption risks, and develop a general model. Next, we develop three separate extensions to the General Model, one for each of the three sourcing strategies discussed in the previous section.

\subsection{The General Model}

We consider a global supply chain where suppliers are spread around the world. There are $h$ possible suppliers, $H=\{1, \ldots, h\}$. We group suppliers that are close together as a set of suppliers in a region (Figure 1). We distinguish suppliers of each region by dividing them into separate sets. $H^{r}$ is defined as the set of suppliers in region $r, R=\{1, \ldots, r\}$, where $H^{1} \cup H^{2} \cup \ldots \cup H^{r}=H$. The firm (manufacturer) has only one facility and the total demand per cycle (single item) is $Q$. We also assume that $Q$ belongs to only one cycle and demand is independent across cycles. Failure to satisfy the demand results in a per-unit financial loss, $L$ (no backlogging). The firm needs to know which suppliers from which regions should be selected, and how many items to allocate tosuppliers in different regions in order to minimize the total cost, while minimizingthe negative (financial) impact of two types of disruptions (suppliers and regions). Definitions of the parameters and variables of the model are provided below. Definitions of the parameters and variables of the model are provided below.

Regions` characteristics: A disruption in a region makes all of the suppliers in that regionunavailable. $P_{r}^{*}$ representsthe probability that regionrwill be disrupted.

Suppliers` characteristics: Each supplier hhas limited capacity, $\operatorname{Cap}_{h}$, that limits its allocation. It is defined as the maximum capability of the supplier to produce and deliver items per cycle.Each supplier 
has its own a price per item, $c_{h}$. Since suppliers are located in different places, transportation cost per item is different for each supplier, $t_{h}$ (Figure1). In Figure 1, we assume that region 1 is closer to the demand point than regions 2 and 3. Consequently, its suppliers are closer and they have lower transportation costs.

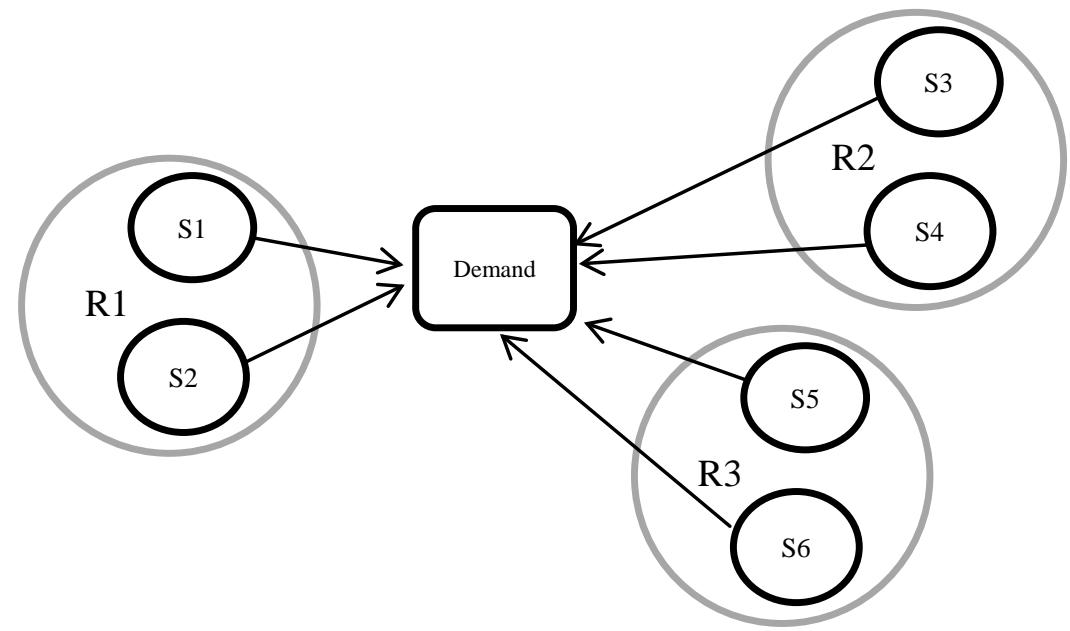

Figure 1. A simple representation of the setting of the model

We assume there is only one cycle; thus, we do not incorporate a time horizon into our models, and we do not evaluate the effects of disruptions and suppliers' reliabilities on subsequentcycles.To incorporate the disruption risk into our model, we assign a disruption probability to each supplier: $P_{h}$ represents the probability of disruption in supplier $h$.Since suppliers do not work in isolation, a disruption in one suppliermay impact other suppliers as well. (Suppose suppliers 1 and 2 share a common secondtier supplier.Suppliers 1 and 2 would both be affected by a disruption in that second-tier supplier, but with different magnitudes.) We reflect the disruption dependence of suppliers by assigning a parameter

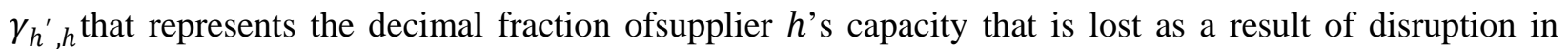
supplier $h^{\prime}$. For example, $\gamma_{h^{\prime}, h}=.25$ means a disruption in $h^{\prime}$ leads to a $25 \%$ reduction in $h^{\prime}$ s capacity; $\alpha_{h^{\prime}, h}=1$ means a disruption in $h^{\prime}$ leads to a $100 \%$ reduction in $h$ 's capacity, or the unavailability of supplier $h$. For mathematical purposes, we assume $\gamma_{h, h}=0$ and $\sum_{h^{\prime} \in H} \gamma_{h^{\prime}, h}=1$. We want to determine which suppliers in the supply base are selected,and how many items would be allocated to the selected suppliers. $Z_{h}$ is a binary variable that represents the selection of supplier $h$, and $a_{h}$ is an integer variable that represents supplier $h$ 's allocation of demand.

Scenarios' characteristics:In the General Model, uncertainty is examined through using a set of discrete scenarios, each with a probability of occurrence. Since disruptions are independent, they may happen in suppliers and regions separately or concurrently. We define $S$ scenarios, $S=\{1, \ldots, s\}$, for different kinds of events that may happen as the result of disruptions. We define $D_{s, h}$ as the disruption status of supplier $h$ 
in scenario s. If supplier $h$ is individually disrupted in scenario $s$ due to supply disruption risks, this parameter is 0. Otherwise, if the supplier is available, or unavailable but because of regional disruptions, (environmental risk) it is 1. (Note that we distinguish a supplier's unavailability due to supplier disruption from that of regional disruptions by using terms "disrupted” and "unavailable”. A supplier is disrupted and unavailable when an individual disruption happens to it. On the other hand, a supplier is unavailable (but not disrupted) when an environmental disruption happens in the region in which it is located. Although the ultimate status of thesupplier is that it is not available in both cases, the first case (“disrupted") is the supplier's fault and may impact other suppliers as well; the second case (“unavailable”) stems from an environmental disaster and does not impact other suppliers' operations in other regions.) It is also important for us to know the state of each region and each supplier in each scenario. Thus, we assign binary parameters $\operatorname{Reg}_{s, r}$ as the state of region $r$ in scenario $s$,and $S_{s, h}$ as the state of supplier $h$ in scenario s. If the region or the supplier is available, the parameter will be equal to one; otherwise it is zero. ( $S_{s, h}$ iszero for supplier $h$ in scenario $s$ if this supplier is unavailable, regardless of whether unavailability stems from supplier disruption or regional disruption.) Based on the two types of events that may disrupt regions and suppliers, we need to define the probability of occurrence for each scenario, $\pi_{s}$. Using the availability and probability parameters, the probability of occurrence for each scenario is determined as:

$\pi_{s}=\prod_{r \in R}\left[\left(1-\operatorname{Reg}_{s, r}\right) P_{r}^{*}+\left(1-P_{r}^{*}\right) \operatorname{Reg}_{s, r} \prod_{h \in H^{r}}\left[\left(1-S_{s, h}\right) P_{h}+\left(1-P_{h}\right) S_{s, h}\right]\right]$

An example of how $\pi_{s}$ is calculated is shown in Figure2. Because the availability of suppliers is dependent on their regions, we first check the region's status. For example,if region 2 is available, $\operatorname{Reg}_{s, 2}=1$, and the probability would be $\left(1-P_{2}^{*}\right)$. Then, we examine the availability of its suppliers and their probabilities. However, if region 2 is disrupted, $\operatorname{Reg}_{s, 2}=0$, the probability would be $P_{2}^{*}$ and the supplier's status is not investigated. 


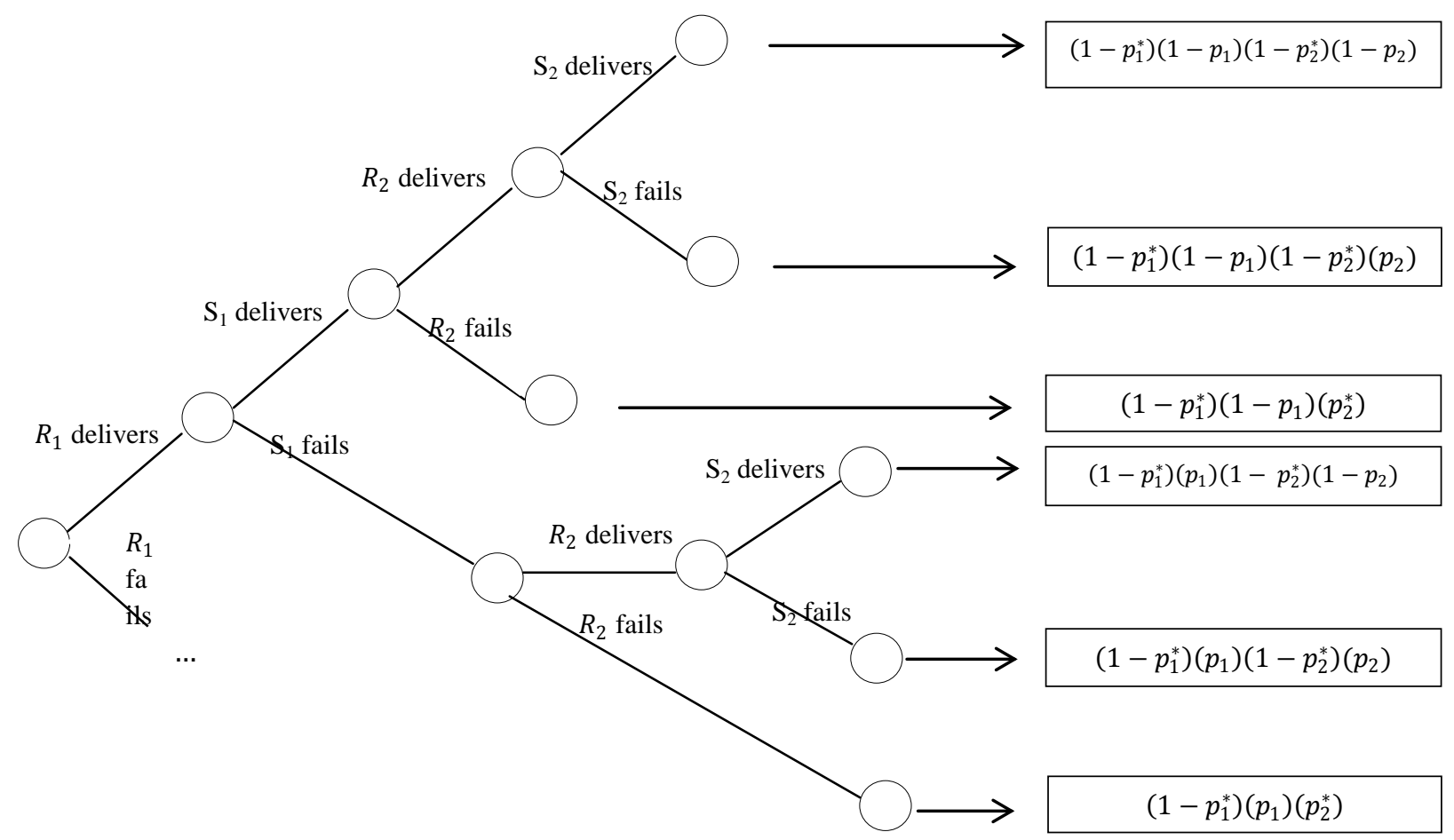

Figure 2. Decision tree for two regions and one supplier in each region

After calculating probabilities for all scenarios, these values will be used to determine the expected total cost.The variables whose values we look for in scenarios includethe quantity of items that flows from supplierh in scenario $s, q_{s, h}$, and the number of unsatisfied items in scenario $s, U_{s}$.

Associated costs: There are four different types of costs associated with the General Model. We divide costs into two categories: first-stage costs and second-stage costs. First-stage costs include costs that a manufacturer should spend in the first stage, prior to having any knowledge about the outcome of any scenario that may happen. In the general model, the only cost that is classified in this category is Supplier Management Cost (SC). Suppliermanagement cost is the cost that the manufacturer incurs in order to manage and maintain relationships with suppliers. As the number of suppliers increases, the complexity of the supply chain increases, which increases SC(Berger et al., 2004; Ruiz-Torres et al., 2013). We assume a fixed cost of $F_{h}$ for adding supplier $h$ to the supply base. The second-stage costs include those costs that are dependent on the settings of the scenario, which is the cost the manufacturer spends in order to respond to that scenario. Second-stage costsinclude Order Cost $\left(O C_{S}\right)$, Transportation Cost $\left(T C_{S}\right)$, and Loss Cost $\left(L C_{s}\right)$, which are the cost of ordering and transporting items from each supplier, and the cost of unsatisfied items in scenario $s$, respectively. The formulas for these associated costs are presented below.

$$
\begin{aligned}
& S C=\sum_{h \in H} F_{h} Z_{h} \\
& O C_{s}=\sum_{h \in H} c_{h} q_{s, h} \\
& T C_{s}=\sum_{h \in H} t_{h} q_{s, h}
\end{aligned}
$$


The expected total cost is the summation of all of the costs that we defined for this model:

Expected Total Cost $=S C+\sum_{s \in S} \pi_{S}\left(O C_{S}+T C_{S}+L C_{S}\right)$

The two-stage mixed-integer programming model for the General Model for supplier selection and allocation with the objective of minimizing expected total costsis shown below:

Minimize $E T C=S C+\sum_{s \in S} \pi_{s}\left(O C_{s}+T C_{s}+L C_{s}\right)$

Subject to:

$$
\begin{array}{lc}
\sum_{h \in H} a_{h}=Q & \\
a_{h} \leq Z_{h} \operatorname{Cap}_{h} & h \in H \\
q_{s, h} \leq a_{h} S_{s, h} & \forall s \in S \& h \in H \\
q_{s, h} \leq \operatorname{Cap}_{h}\left(1-\sum_{h^{\prime} \in H}\left(1-D_{s, h^{\prime}}\right) \gamma_{h^{\prime}, h}\right) & \forall s \in S \& h \in H \\
U_{s}=Q-\sum_{h \in H} q_{s, h} & \forall s \in S \\
Z_{h}=\{0,1\}, a_{h} \geq 0, q_{s, h} \geq 0, U_{s} \geq 0 & \forall s \in S \& h \in H
\end{array}
$$

Constraint (C1) is used to allocate the demand among suppliers. Constraint (C2) ensures that the allocation of each supplier will be limited by its capacity, if the supplier is selected in the supply base. Constraint (C3) ensures that flow of materialsfrom each supplier in each scenario does not exceed its allocation, and it depends on the availability of the supplier in that scenario. Constraint (C4) represents the dependence of suppliers on each other. It indicates that the quantity of outflow items from each supplier should be less than its available capacity, and it loses $\gamma_{h^{\prime}, h}$ of its capacity in each scenario where it depends on supplier [h prime] and that supplier is disrupted. Constraint (C5) determines the number of unsatisfied items in each scenario by subtracting from the total demand the summation of the quantities that flow from all suppliers.Constraint (C6) is a non-negativity constraint.

The General Model is a two-stage mixed-integer programming model. The first-stage decisions are determined through incorporating uncertainty of the future outcomes. The second-stage decisions are then evaluated after the potential future outcomes are assessed; thus, the second-stage decisions are conditional on the first-stage decisions (Birge and Louveaux 1997, Rawls and Turnquist 2010). Here $Z_{h}$ variables, or selection of suppliers, are first-stage decisions, made prior to having knowledge of any specific scenario's outcome.The objective function in the first stage is minimization of Supplier Management Costs (SC), and expected total cost of ordering, transportation, and loss costs of supplies over all possible disruptions. The $q_{s, h}$ variables, which represent quantity flow from each supplier in each scenario, are scenariodependent variables, and constitute the second-stage decisions. The objective function in the second stage is minimization of the all the scenario-dependent costs including order, transportation, premium, and loss costs, considering the probability of occurrence of each scenario. 
The deterministic equivalent program of this model is a mixed-integer program (MIP) where the first- and second-stage decisions are integrated and the model is being solved in the extensive form. The solution to relatively small problems can be determined by creating the equivalent deterministic MIP model. This can be accomplished using commercial MIP software (Rawls and Tranquist 2010, Qin et al. 2013). In this study, CPLEX 12.6 was used as a powerful tool for solving MIP problems. Please note that all of the extended model that we represent later were also solved in deterministic equivalent form.

The model first calculates the probability of occurrence for each scenario using a decision tree. Usingtwo-stage mixed-integer programming, it will provide the optimal solution for selection of the best set of suppliers and allocation of demand across them in order to minimize the expected total cost.In addition, the contingency plans for each scenario are included in the optimal solution.

\subsection{Extensions to the General Model for each sourcing strategy}

In the next sections, we develop three separate extensions of the General Model, to examine the impact of thethree sourcing strategies. We introducea new parameter, $B_{0}$, as pre-disruption budgetin order to limit the manufacturer's budget on disruption mitigation strategies. Pre-disruption budget is the budget that the manufacturer can invest before the disruption happens (e.g.,holding inventory, building warehouses, or protecting suppliers). Below, a more detailed review for each sourcing strategy is provide

\subsubsection{Pre-positioning Inventory Model}

The following extensionsare added to theGeneral Model to develop the Pre-positioning Inventory Model. The emergency supplies must be pre-positioned in pre-positioning warehouses and must be purchased in advance from suppliers.After disruptions happen (leading to unavailability of a number of suppliers), the excess inventory at warehouseswill be used to satisfy the demand (Figure3). Here we review the warehouses' characteristics.

Warehouse characteristics: We assume that the manufacturer has the ability to build warehouses in different regions. Since this paper does not focus on facility location problems, we assume the location of each warehouse has been selected and there are $w$ options, $W=\{1, \ldots, w\}$, to build the warehouse. Each warehouse has a specific capacity, $\operatorname{Cap}_{w}$, and fixed building cost, $M_{w}$. We also define $t w_{w}$ as the transportation cost for each item from warehouse $w$ to the demand point and $t s w_{h, w}$ as the transportation cost for each item delivered to warehouse $w$ from supplier $h$.Finally,hold $d_{w}$ is defined as the holding cost per item pre-positioned in warehousew. It is assumed thathold $w_{w}$ is constant, regardless of the time. It is also important to indicate that a disruption in a region will cause unavailability of both the suppliers and the warehouse. Let $W_{s, w}$ represent the delivering status for warehouse $w$ in scenario $s$. Thus, $W_{s, w}=1$ for active warehouses in scenario $\mathrm{s}$, and $W_{s, w}=0$ for unavailable ones.After a disruption is detected, available inventories (at warehouses) are used to make up unsatisfied items. Following this new assumption, we add these variables to the General Model: 
- $Y_{w}$ represents the selection of warehouse type wto be built

- $\quad b_{h . w}$ represents the number of items purchased from supplier hto be pre-positioned at warehouse w

- $\quad p_{s . w}$ represents the number of items delivered to the demand pointin scenario $s$ from warehouse $w$

Figure 3 presents an example of the proposed model with pre-positioning inventory. $R 1$ and $R 2$ represent regions, $S 1$ to $S 6$ represent suppliers, $W$ represents the warehouses in each region. The solid arrows show the delivery paths from suppliers to the demand point. The orangedashed arrows represent the delivery paths for pre-positioning inventories from suppliers to warehouses prior to disruption. Finally, black dotted arrows represent delivery paths in disruption when emergency items are transported from warehouses to the demand point.

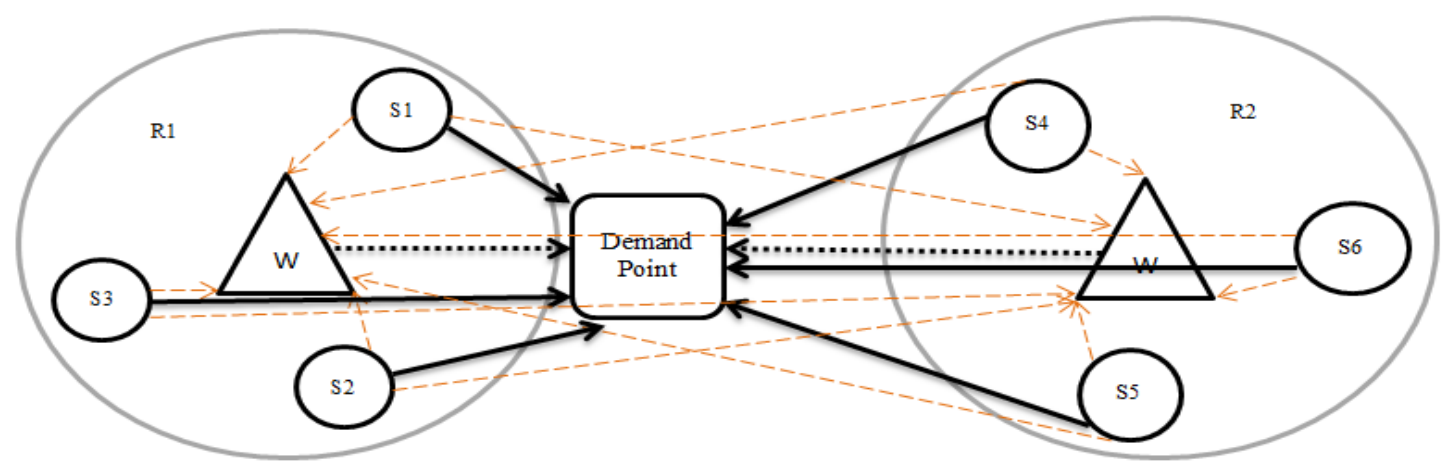

Figure 3. Pre-positioning Inventory Model with all possible links between nodes

Associated costs: Similar to the General Model, associated costs are divided into two categories. In the first category (first-stage costs), in additionto the Supplier Management Cost (SC) explained previously, we have the following cost items:

- Warehouse Building Cost (WC) -- the cost that the manufacturer should invest to build warehouses

- Emergency Inventory Order Cost (EOC) -- the investment for purchasing emergency inventories from suppliers

- Emergency Inventory Transportation Cost from Suppliers to Warehouses (ETSW) -- the cost of transporting emergency inventory to warehouses

- Emergency Inventory Holding Cost (EHC) -- the cost of holding emergency inventory in the warehouses

Second-stage costs, the costs that a manufacturer must spend to respond to disruptions are:

- Order Cost $\left(O C_{S}\right)$ and Transportation Cost from Suppliers $\left(T C_{s}\right)$ for purchasing and transporting the normal allocation of each available supplier 
- Emergency Inventory Transportation Cost from Warehouses $\left(\mathrm{ETW}_{s}\right)$ for transporting prepositioned emergency inventoryfrom warehouses in order to makeupfor disrupted suppliers' allocations

- $\quad$ Loss Cost $\left(L C_{s}\right)$ for the items that remained unsatisfied at the end of the cycle

The associated costs are expressed in (PP1)-(PP9) as shown below.

$$
\begin{aligned}
& S C=\sum_{h \in H} F_{h} Z_{h} \\
& W C=\sum_{w \in W} M_{w} Y_{w} \\
& E O C=\sum_{h \in H} \sum_{w \in W} c_{h} b_{h, w} \\
& E T S W=\sum_{h \in H} \sum_{w \in W} t_{S w_{h, w}} b_{h, w} \\
& E H C=\sum_{h \in H} \sum_{w \in W} \text { hold }_{w} b_{h, w} \\
& O C_{s}=\sum_{h \in H} c_{h} q_{s, h} \\
& T C_{s}=\sum_{h \in H} t_{h} q_{s, h} \\
& E T W_{s}=\sum_{w \in W} t w_{w} p_{s, w} \\
& L C_{s}=L U_{s}
\end{aligned}
$$

The expected total costs for this model would be:

Expected Total Cost $=$

$S C+W C+E O C+E T S W+E H C+\sum_{s \in S} \pi_{s}\left(O C_{s}+T S_{S}+E T W_{s}+L C_{s}\right)$

Shown below is the two-stage mixed-integer programming model forthe pre-positioning inventory strategyto develop a sourcing decision using suppliers, warehouses, and emergency inventory, with the objective of minimizing expected total costs.

Minimize $E T C=S C+W C+E O C+E T S W+E H C+\sum_{s \in S} \pi_{S}\left(O C_{s}+T C_{s}+E T W_{s}+L C_{s}\right)$

Subject to:

$$
\begin{array}{lc}
\sum_{h \in H} a_{h}=Q & \\
a_{h} \leq Z_{h} \operatorname{Cap}_{h} & h \in H \\
q_{s, h} \leq a_{h} S_{s, h} & \forall s \in S \& h \in H \\
q_{s, h} \leq \operatorname{Cap}_{h}\left(1-\sum_{h^{\prime} \in H}\left(1-D_{s, h^{\prime}}\right) \gamma_{h^{\prime}, h}\right) & \forall s \in S \& h \in H \\
\sum_{h \in H} b_{h, w} \leq Y_{w} \operatorname{Cap}_{w} & \forall w \in W \\
\sum_{w \in W} b_{h, w} \leq Z_{h} \operatorname{Cap}_{h}-a_{h} & \forall h \in H \\
p_{s, w} \leq W_{s, w} \sum_{h \in H} b_{h, w} & \forall s \in S \& w \in W \\
\sum_{w \in W} p_{s, w} \leq \sum_{h \in H} a_{h}\left(1-S_{s, h}\right) & \forall s \in S \\
U_{S}=Q-\left(\sum_{h \in H} q_{s, h}+\sum_{w \in W} p_{s, w}\right) & \\
W C+E O C+E T S W+E H C \leq B_{0} &
\end{array}
$$




$$
Z_{h}=\{0,1\}, Y_{w}=\{0,1\}, a_{h} \geq 0, b_{h, w} \geq 0, q_{s, h} \geq 0, p_{s, h} \geq 0, U_{s} \geq 0 \forall s \in S \& h \in H \& w \in W(\mathrm{C} 11)
$$

As we explained in the previous model, constraints (C1), (C2), and (C3) are used to allocatedemand among suppliers, taking into account their limitations on allocations and each supplier's availability andoutputin different scenarios. Constraint (C4) again represents the reduction in a supplier's capacity when there are disruptions in other suppliers on whom it is dependent. Constraint (C5) ensures that the number of pre-positioned items in each warehouse (satisfied by all suppliers) must be less than or equalto its capacity. Constraint (C6) requires that the number of pre-positioned items satisfied by each supplier (to all warehouses) be less than or equal toits available capacity (available capacity is a supplier'sexcess capacity after its allocationis subtracted from the full capacity). Constraint (C7) indicates that the quantity of items used from each warehouse in each scenario must be less than the total of prepositioned items in it. Constraint (C8) serves two purposes: it eliminates use of emergency inventory when there is no disruption;andit limits the quantity of emergency items to the allocation of disrupted suppliers in that specific scenario. Constraint (C9) is used to calculatethe number of unsatisfied items in each scenario. Constraint (C10)limits the pre-disruption costs of Warehouse Building Cost, Emergency Inventory Order Cost,Transportation Cost from Suppliers to Warehouses, and Emergency Inventory Holding Cost at warehousesto an exogenous pre-disruption budget, $B_{0}$. Constraint (C11) is a nonnegativity constraint.

This is a two-stage mixed-integer programmingmodel that can examine pre- and post-disruption decisions. These are the first-stage decisions, determinedprior to the disruption: $Z_{h}$ (selection of suppliers), $Y_{w}$ (selection of warehouses), and $b_{h, w}$ (number of emergency inventories allocated to suppliers to be prepositioned at warehouses). Second-stage decisions are scenario-dependent variables: $q_{s, h}$ (quantity flow from each supplier in each scenario), and $p_{s, w}$ (quantity flow from each warehouse in each scenario).

\subsubsection{Backup Suppliers Model}

To develop the Backup Suppliers Model from the General Model, we add extensionsfor primary and secondary suppliers. The manufacturer divides suppliers into primary and secondary suppliers. Primary suppliers are those that satisfy demand during the normal situation. Secondary suppliers are backup suppliers, which are used only when disruption happens in primary suppliers. Therefore, secondary suppliers must produce the allocations they receive for emergency inventory, and keep them in their warehouses. Whena primary supplier becomes unavailable, emergency inventory in backup suppliers will be transported to the demand point to makeupunavailable suppliers' allocations. Figure 4 shows an example of a proposed model for disruption that incorporates backup suppliers. The dotted arrows are flows of emergency inventory from backup suppliers in disruptions. The solid arrows are flows of suppliers in normal conditions. In this example,suppliers S3 and S5 are backup suppliers. 
Backup suppliers` characteristics: Each supplier has two different prices for products:one for the normal situation, $c_{h}$, and one for disruptions, $g_{h}$, when it is used as a backup supplier. It is assumed thatthe disruption price is higher than the normal price $\left(g_{h}>c_{h}\right)$. Contracting with backup supplier $h$ has a fixed cost, $G_{h}$. Once the supplier is selected as a backup supplier, it produces the amount allocated to it as emergency inventory, and keepsit in its warehouse. The supplier will charge hold $h_{h}$ as holding cost for keeping one emergency inventory in its warehouse. We assume holding cost is constant, regardless of the time. Each backup supplier has a limited capacity for keeping emergency items, ECap .

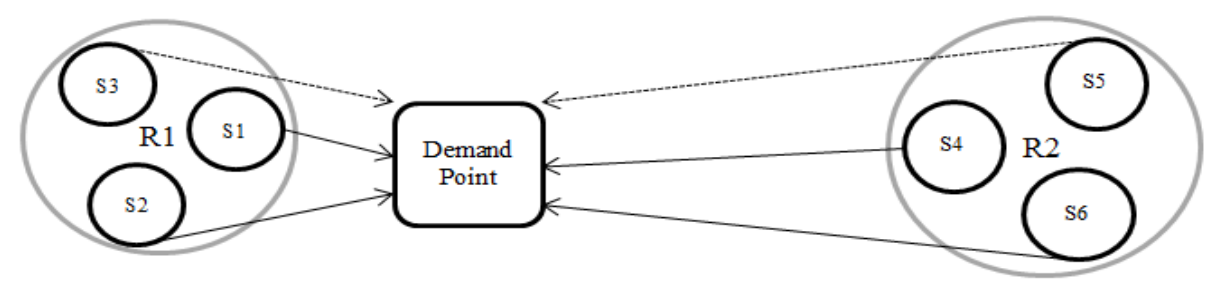

Figure 4. Backup Suppliers Model.

The decisions that need to be made are the selection of backup suppliers, $K_{h}$, the allocation of emergency inventory for each one, $b_{h}$, and the quantities that flow from backup suppliers in each scenario, $p_{s, h}$. Note that a backup supplier may be unavailable in some scenarios, since it isalso exposed to supplier and regionaldisruptions.

Associated costs: Theassociated costs are divided into two categories. For first-stage costs,in addition to the Supplier Management Cost (SC) from the general model, we have:

- Backup Contracting Cost (BC)-- cost of developing contracts with backup suppliers

- Emergency Inventory Holding Cost (EHS)-- cost of holding emergency inventory in suppliers' warehouses

The second-stage costs are:

- Order Cost $\left(O C_{S}\right)$ andTransportation Cost $\left(T C_{S}\right)$-- costs for purchasing and transportation of the available suppliers'allocations

- Emergency Inventory Order $\operatorname{Cost}\left(E O C_{s}\right)$ andEmergency Inventory Transportation Cost $\left(E T C_{S}\right)$-costs for purchasing and transportation of emergency inventory from backup suppliers

- Loss Cost $\left(L C_{s}\right)$ - cost for unsatisfied items at the end of the cycle

The associated costs are calculated in (B1)-(B8) as shown below:

$S C=\sum_{h \in H} F_{h} Z_{h}$

$B C=\sum_{h \in H} G_{h} K_{h}$

$E H C=\sum_{h \in H}$ hold $_{h} b_{h}$ 


$$
\begin{aligned}
& O C_{s}=\sum_{h \in H} c_{h} q_{s, h} \\
& T C_{s}=\sum_{h \in H} t_{h} q_{s, h} \\
& E O C_{s}=\sum_{h \in H} g_{h} p_{s, h} \\
& E T C_{s}=\sum_{h \in H} t_{h} p_{s, h} \\
& L C_{s}=L U_{s}
\end{aligned}
$$

The Expected total costs for this model would be:

Expected Total Costs $=S C+B C+E H C+\sum_{s \in S} \pi_{s}\left(O C_{s}+T C_{s}+E O C_{s}+E T C_{s}+L C_{s}\right)$

Shown below is the two-stage mixed-integerprogramming model for the backup suppliersstrategy to develop a sourcing decision using primary suppliers,backup suppliers, and emergency inventory, with the objective of minimizing expected total costs.

Minimize $E T C=S C+B C+E H C+\sum_{s \in S} \pi_{S}\left(O C_{s}+T C_{s}+E O C_{s}+E T C_{s}+L C_{s}\right)$

Subject to:

$$
\begin{array}{ll}
\sum_{h \in H} a_{h}=Q & \\
a_{h} \leq Z_{h} \operatorname{Cap}_{h} & h \in H \\
q_{s, h} \leq a_{h} S_{s, h} & \forall s \in S \& h \in H \\
q_{s, h} \leq \operatorname{Cap}_{h}\left(1-\sum_{h^{\prime} \in H}\left(1-D_{s, h^{\prime}}\right) \gamma_{h^{\prime}, h}\right) & \forall s \in S \& h \in H \\
Z_{h}+K_{h} \leq 1 & h \in H \\
b_{h} \leq K_{h} E_{C a p} & h \in H \\
p_{s, h} \leq b_{h} S_{s, h} & \forall s \in S \& h \in H \\
p_{s, h} \leq \sum_{h \in H} a_{h}\left(1-S_{s, h}\right) & \forall s \in S \& h \in H \\
p_{s, h} \leq E C a p_{h}\left(1-\sum_{h^{\prime} \in H}\left(1-D_{s, h^{\prime}}\right) \gamma_{h^{\prime}, h}\right) & \forall s \in S \& h \in H \\
U_{s}=Q-\sum_{h \in H}\left(q_{s, h}+p_{s, h}\right) & \\
B C+E H C \leq B_{0} & \geq 0, U_{s} \geq 0 \forall s \in S \& h \in H \\
Z_{h}=\{0,1\}, K_{h}=\{0,1\}, a_{h} \geq 0, b_{h} \geq 0, q_{s, h} \geq 0, p_{s, h}
\end{array}
$$

Constraints (C1), (C2), and(C3) allocate demand among suppliers, limit the allocations to suppliers' capacities, and limit the quantity flow from each supplier in each scenario to its allocation and its availability.Constraint (C4) represents the dependence of suppliers to each other and reduction in primary suppliers' output in case of disruptions in other suppliers. Constraint (C5) indicates that one supplier can be either in the supply base or as a backup supplier. Constraint (C6) limits the allocation of emergency inventory in backup suppliers to their emergency capacities.Constraint (C7) limits the quantity flow from backup suppliers to the allocation of emergency inventory and backup suppliers' availabilities. Constraint (C8) eliminatesuse of emergency inventory when there is no disruption and ensures that the quantity assigned as emergency inventorydoes not exceed the quantity that was supposed to be delivered 
by disrupted suppliers if they were available.Constraint (C9) represents the dependence of backup suppliers' output on other suppliers' disruption. Constraint (C10) calculates the number of unsatisfied items in each scenario. Constraint (C11) restrictsBackup Contracting Cost andEmergency Inventory Holding Costto a pre-disruption budget, $B_{0}$. Constraint (C12) is a non-negativity constraint. This is a twostage mixed-integer programmingmodel that examines both pre-and post-disruption decisions. These are the first-stage decisions, made prior to a disruption: $Z_{h}$ (selection of suppliers); $K_{h}$ (selection of backup suppliers); and $b_{h}$ (number of emergency inventory to be pre-positioned at each backup supplier). The second-stage decisions are scenario-dependent variables: $q_{s, h}$ (quantity flow from each primary supplier in each scenario); and $p_{s, h}$ (quantity flow from each backup supplier in each scenario).

\subsubsection{Protected Suppliers Model}

The final model incorporates the protected supplier'sstrategy. Theextensionsdescribed below are added to the General Model.

The manufacturer can improve the reliability of its suppliers. By making an investmentin a supplier, the likelihood of a disruption occurring in that supplier will be reduced. We assume that the disruption probability in that supplier will be close to zero.Protecting a supplier minimizesthat supplier's disruptions, but there is still the probability of disruption in that supplier's region. By holding emergency inventory in protected suppliers, we can mitigate the effects of disruptions in unprotected suppliers. The manufacturer allocates emergency inventory to protected suppliers. Each protected supplier is responsible to produce and keep its allocation of emergency inventory in its warehouse and deliver it when disruption happens in an unprotected supplier. Figure 5 shows an example of the proposed model for disruption with protected and unprotected suppliers. In this figure, suppliers 3 and 5 are assumed to be protected, and the arrows that show the delivery paths are bolded for these suppliers to emphasize that those arrows cannot be cut, unless a regional disruption cuts them.

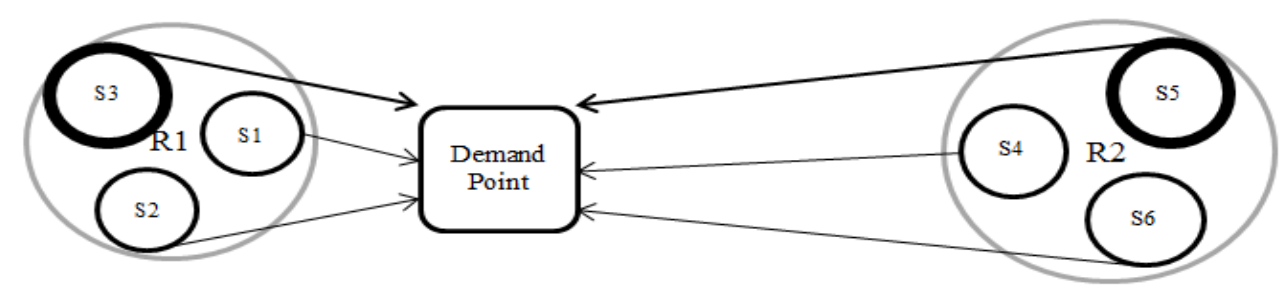

Figure 5. Protected Suppliers Model

Protected suppliers' characteristics: Protecting supplier $h$ has a fixed cost, $G_{h}$. Each protected supplier has an emergency capacity, $E C a p_{h}$, and chargesa holding cost per item,hold ${ }_{h}$, for those items kept in the warehouse as emergency inventory. This supplier then sells these items at a different selling price, $g_{h}$, which is higher than the normal selling price of the supplier $\left(g_{h}>c_{h}\right)$. We assume the holding cost is constant.We want to determine which supplier(s) should be protected, $P r_{h}$, how emergency inventory 
should be kept at protected supplier $h, b_{h}$, the quantity of items that flow from protected and also unprotected supplier $h$ in scenario $s, q_{s, h}$, and the quantity of emergency items that flow from protected supplier $h$ in scenario $s, p_{s, h}$. Note that protected suppliers are also exposed to regional disruptions. Thus, we assign a binary parameter for their status in different scenarios. Let $S P_{s, h}$ represent the status of protected supplier $h$ in scenario $s$. This parameter would be equal to 0 for all scenarios in which regional disruption happens where protected suppliers are located. In all other scenarios, $S P_{s, h}=1$.

Associated Costs: Theassociated costs are divided into two categories. These are thefirst-stage costs, in addition to the Supplier Management Cost (SC) from the general model:

- ProtectedSuppliers Cost (PC) -- the investment by the manufacturerin suppliersto protect the suppliers

- Emergency Inventory Holding Cost (EHS)-- cost of holding emergency inventory in protected suppliers

Thesecond-stage costs are scenario-dependent:

- $\quad$ Order Cost $\left(O C_{S}\right)$ andTransportation Cost $\left(T C_{S}\right)$ for purchasing and transportation of items from available suppliers

- Emergency Inventory Order $\operatorname{Cost}\left(E O C_{s}\right)$ andEmergency Inventory Transportation Costs (ETC $)$ for purchasing and transportation of emergency inventory in disruption from protected suppliers

- Loss Cost $\left(L C_{s}\right)$ for unsatisfied items at the end of the cycle

These associated costs are calculated in (P1)-(P8) as shown below:

$S C=\sum_{h \in H} F_{h} Z_{h}$

$P C=\sum_{h \in H} G_{h} P r_{h}$

$E H C=\sum_{h \in H}$ hold $_{h} b_{h}$

$O C_{s}=\sum_{h \in H} c_{h} q_{s, h}$

$T C_{s}=\sum_{h \in H} t_{h} q_{s, h}$

$E O C_{s}=\sum_{h \in H} g_{h} p_{s, h}$

$E T C_{s}=\sum_{h \in H} t_{h} p_{s, h}$

$L C_{s}=L U_{S}$

This is theexpected total cost (ETC) for this model:

$\mathrm{ETC}=S C+P C+E H C+\sum_{s \in S} \pi_{s}\left(O C_{s}+T C_{s}+E O C_{s}+E T C_{s}+L C_{s}\right)$

Shown below is the two-stage mixed-integer protected suppliersmodel to develop a sourcing decision using protected suppliers, unprotected suppliers, and emergency supplies, with the objective of minimizing expected total costs.

Minimize $E T C=S C+P C+E H C+\sum_{s \in S} \pi_{s}\left(O C_{s}+T C_{s}+E O C_{s}+E T C_{s}+L C_{s}\right)$ 
Subject to:

$$
\begin{array}{ll}
\sum_{h \in H} a_{h}=Q & \\
a_{h} \leq Z_{h} \operatorname{Cap}_{h} & h \in H \\
b_{h} \leq \operatorname{Pr}_{h} \operatorname{CCap}_{h} & h \in H \\
\operatorname{Pr}_{h} \leq Z_{h} & h \in H \\
q_{s, h} \leq a_{h} & \forall s \in S \& h \in H \\
q_{s, h} \leq \operatorname{Cap}_{h}\left(\operatorname{Pr}_{h}\left(S P_{s, h}\right)+\left(1-\operatorname{Pr}_{h}\right) S_{s, h}\right) & \forall s \in S \& h \in H \\
q_{s, h} \leq \operatorname{Cap}_{h}\left(1-\sum_{h^{\prime} \in H}\left(1-\operatorname{Pr}_{h^{\prime}}\right)\left(1-D_{s, h^{\prime}}\right) \gamma_{h^{\prime}, h}\right) & \forall s \in S \& h \in H \\
p_{s, h} \leq b_{h} S P_{h} & \forall s \in S \& h \in H \\
\sum_{h \in H} p_{s, h} \leq \sum_{h \in H}\left(a_{h}-q_{s, h}\right) & \forall s \in S \\
p_{s, h} \leq E C a p_{h}\left(1-\sum_{h^{\prime} \in H}\left(1-\operatorname{Pr}_{h^{\prime}}\right)\left(1-S_{s, h^{\prime}}\right) \gamma_{h^{\prime}, h}\right) & \forall s \in S \& h \in H \\
U_{s}=Q-\sum_{h \in H}\left(q_{s, h}+p_{s, h}\right) & \forall s \in S \\
P C+E H C \leq B_{0} & \\
Z_{h}=\{0,1\}, \operatorname{Pr}_{h}=\{0,1\}, a_{h} \geq 0, b_{h} \geq 0, q_{s, h} \geq 0, p_{s, h} & \geq 0, U_{s} \geq 0 \forall s \in S \& h \in H
\end{array}
$$

Constraints (C1) and (C2)are used to allocate the demand among suppliers, and limit the allocations. Constraint (C3) limits the allocation of emergency inventory for protected suppliers. Constraint (C4) indicates that one supplier must be selected in the supply base in order to be protected. Constraint (C5) indicates that the quantity flow from suppliers must be less than the allocation.Constraint (C6) limits the quantity flow from suppliers, but differentiates the quantities that flow from protected suppliers from the quantities that flow from unprotected suppliers. Based on this constraint, if the supplier is protected, the availability of suppliers is determined by means of $S P_{s, h}$, which is equal to 1 unless regional disruption makes the protected supplier unavailable, and then $S P_{s, h}=0$. If the supplier is unprotected, the availability of the supplier is determined by means of $S_{s, h}$, whose value is affected by both supplier and regional disruptions. Constraint (C7) limits output of suppliers to unprotected suppliers' disruption. (Protected suppliers would not experience individual disruption.) Constraint (C8)shows that the quantity of emergency inventorythat flows from a protected supplier in different scenarios depends on its allocation, and the availability of the supplier (i.e., no regional disruption in its region). Constraint (C8) ensures that the quantity of emergency inventory needed in each scenario should beless than or equalto the quantity that was supposed to be delivered by disrupted suppliers if they were available.Constraint (C9) is used to find the number of unsatisfied items in each scenario. Constraint (C10) limits emergency output of protected suppliers to unprotected suppliers' disruption. Constraint (C11) shows the restriction of Protection Cost and Emergency Inventory Holding Costto a pre-disruption budget, $B_{0}$. Constraint (C12) is a non-negativity constraint.This model is a two-stage mixed-integer 
programming model that can cover both pre- and post-disruption decisions. These are the first-stage decisions, made before there is knowledge of any specific scenario outcome: $Z_{h}$ (selection of suppliers); $P r_{h}$ (selection of protected suppliers); and $b_{h}$ (number of emergency inventory to be prepositioned at each protected supplier). Second-stage decisions are scenario-dependent variables: $q_{s, h}$ (quantity of normal items flow from eachsupplier in each scenario), and $p_{s, h}$ (quantity of emergency inventory flow from each protected supplier in each scenario).

\section{Case Study and Computational Examples}

In this section, computational examples are presented to illustrate applications of the proposed two-stage mixed-integer programming models for supplier selection and demandallocation in a supply chain with supply and environmental disruption risks. First, we define a numerical example for the General Model. Later, we expand the example to examine the impact of each supply disruption mitigation strategy. The example usesthe data and the model presented by Ruiz-Torres et al. (2013)and Kamalahmadi and Mellat-Parast (2016b), based on observing a global manufacturer ofappliances. We modify some of the parameters in order to make it applicable to our decision model. For the new parameters, we estimate the values based on the suggestions in the literature.

\subsection{General Model example}

We consider six suppliers in three clusters as regions 1,2 , and $3, r^{1}, r^{2}$, and $r^{3}$. Two suppliers exist in each region, $H^{1}=\{1,2\}, H^{2}=\{3,4\}$, and $H^{3}=\{5,6\}$. All of the suppliers are first-tier suppliers for the demand point (the firm). Therefore, they provide the same item with different cost,reliability, and production capacity. From region 1 to region 3, suppliers provide items withlower prices and higher capacity. However, they are less reliable and more likely to experience disruption. We also assume that suppliers in the first region are closer to the manufacturer, and hence the transportation cost is lower for this region.In addition, we assume that since regions 2 and 3 are farther from the demand point, they are more exposed to environmental risks and disruptions. Data on suppliers and regions are shown in Table 1.The information about suppliers' dependence on one another is presented in Table 2. For example, Table 2 indicates that a disruption in supplier 1 will reduce the capacity of supplier 2 by $20 \%$ and that of supplier 3 by 10\%. The demand and loss cost per item is assumed to be 4000 and 400 , respectively. The proposed model was developed and solved by IBM ILOG CPLEX optimization software.

Table 1. Suppliersand Regions Data

\begin{tabular}{|c|c|c|c|c|c|c|}
\hline & \multicolumn{2}{|c|}{ Region 1 } & \multicolumn{2}{c|}{ Region 2 } & \multicolumn{2}{c|}{ Region 3 } \\
\hline $\begin{array}{c}\text { Disruption } \\
\text { probability }\end{array}$ & \multicolumn{2}{|c|}{$0.05 \%$} & \multicolumn{2}{|c|}{$1 \%$} & \multicolumn{2}{c|}{$2 \%$} \\
\hline Suppliers & S[1] & S[2] & S[3] & S[4] & S[5] & S[6] \\
\hline Capacity (items) & 1000 & 1500 & 2000 & 2500 & 3000 & 3500 \\
\hline Order Cost (\$/item) & 25 & 22 & 20 & 15 & 12 & 10 \\
\hline
\end{tabular}




\begin{tabular}{|c|c|c|c|c|c|c|}
\hline $\begin{array}{c}\text { Transportation Cost } \\
\text { (\$/item) }\end{array}$ & 5 & 6 & 7 & 8 & 9 & 10 \\
\hline $\begin{array}{c}\text { Disruption } \\
\text { probability }\end{array}$ & $1 \%$ & $2 \%$ & $4 \%$ & $6 \%$ & $8 \%$ & $10 \%$ \\
\hline Fixed cost (\$) & 1000 & 1000 & 1000 & 1000 & 1000 & 1000 \\
\hline
\end{tabular}

Table 2. Suppliers’ Dependence

\begin{tabular}{|c|c|c|c|c|c|c|}
\hline & $\mathrm{S}[1]$ & $\mathrm{S}[2]$ & $\mathrm{S}[3]$ & $\mathrm{S}[4]$ & $\mathrm{S}[5]$ & $\mathrm{S}[6]$ \\
\hline $\mathrm{S}[1]$ & - & 0.5 & 0.3 & 0.1 & 0 & 0 \\
\hline $\mathrm{S}[2]$ & 0.2 & - & 0.2 & 0 & 0 & 0 \\
\hline $\mathrm{S}[3]$ & 0.1 & 0.2 & - & 0.1 & 0.1 & 0 \\
\hline $\mathrm{S}[4]$ & 0 & 0.2 & 0.3 & - & 0 & 0.2 \\
\hline $\mathrm{S}[5]$ & 0 & 0 & 0.2 & 0 & - & 0.5 \\
\hline $\mathrm{S}[6]$ & 0 & 0.1 & 0 & 0.4 & 0.5 & - \\
\hline
\end{tabular}

Given that there are six suppliers from three regions, 125 scenarios are possible: $2^{6}$ scenarios for 6 suppliers with all three regions available, $3 * 2^{4}$ scenarios with a single regional disruption, $3 * 2^{2}$ scenarios with simultaneous regional disruptions in 2 regions, and 1 scenario with simultaneous regional disruptions in all 3 regions. Recall that in the General Model, we assumed that the manufacturer relies solely on a multi-sourcing strategy to cope with supplier and environmental disruptions. After running the simulation, the optimal solution is the selection of suppliersS[1] and S[2] from region 1 and S[3] from region 2; the allocation of demand is 1800 items to supplier S[1], 2000 items to supplier S[2], and 200items to supplier S[3]. The result is shown in Figure 6.

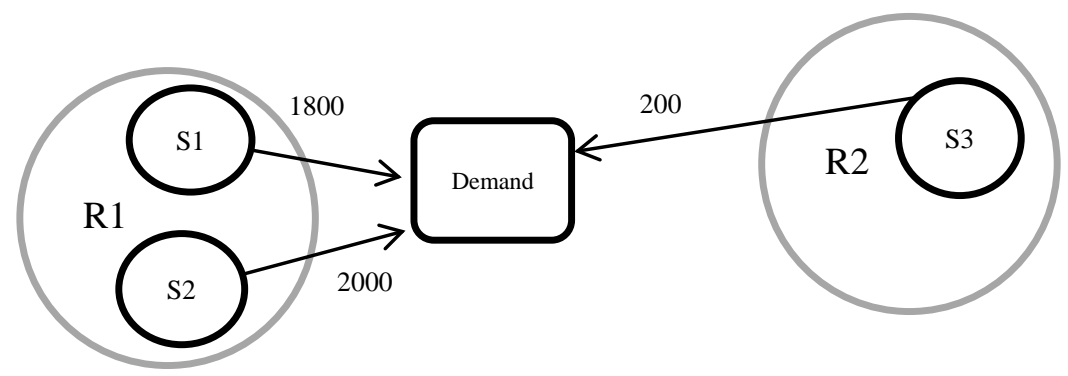

Figure 6. General model solution

The expected total cost for the General Model is $\$ 156,388.00$. With probability of $91.2 \%$, the manufacturer satisfies all the demand. Reviewing suppliers' characteristics indicates that suppliers S[1], $\mathrm{S}[2]$, and S[3] are the most reliable but most expensive suppliers. Although the initially specified capacities of suppliersS[1] and S[2] would be enough to cover the entire demand, disruption in other suppliers (whether or not they are selected in the supply base) reduces the available capacities of these two suppliers, sosupplier S[3] was added to the supply base to mitigate this impact. Now, disruption in suppliers does not impact the allocation of the chosen suppliers. This finding (selection of the most reliable and most expensive suppliers) suggests that if managers want to 
rely entirelyon a multi-sourcing strategy against disruptions, the reliability factor outweighs the cost factor, and selection of the most reliable and expensive suppliers can help the firm minimize the expected total cost.

\subsection{Pre-positioning Inventory Model example}

The first disruption mitigation strategy uses pre-positioning inventoryas redundant resources. We assume that one warehouse can be built in each region to keep emergency inventories. Table 3 shows the capacity and building cost of each warehouse, the transportation cost from each supplier to each warehouse, and the transportation cost from each warehouse to the demand point.We also assume that with the same amount of money (Building Cost), the manufacturer would be able to build a bigger warehouse (capacity) in the second and third region.As the manufacturer experienceda cost of about $\$ 150,000.00$ with no disruption management strategy, we assume that he wants to invest at most $\$ 100,000.00$ as pre-disruption budgets(We will also use $\$ 100,000$ for the pre-disruption budget in each of the next two models). In addition, we assume the value for holding cost per item is $\$ 5$.

Table 3. Warehouse Data

\begin{tabular}{|l|c|c|c|}
\hline & Region 1 & Region 2 & Region 3 \\
\hline Warehouses & W[1] & W[2] & W[3] \\
\hline Capacity (items) & 1500 & 2000 & 2500 \\
\hline Building Cost (\$) & 5000 & 5000 & 5000 \\
\hline $\begin{array}{l}\text { Transportation Cost } \\
\text { (\$/item) from: }\end{array}$ & \multicolumn{3}{|l}{} \\
\hline S[1] & 1 & 5 & 8 \\
\hline S[2] & 2 & 4 & 7 \\
\hline S[3] & 4 & 1 & 5 \\
\hline S[4] & 5 & 2 & 4 \\
\hline S[5] & 7 & 5 & 2 \\
\hline S[6] & 8 & 4 & 1 \\
\hline Demand Point & 2 & 5 & 8 \\
\hline
\end{tabular}

After we ran the model, the optimal solution is selection of four suppliers, twoof the first region and two of the third regionin the supply base, plus building one warehouse in the second region. The optimal allocation among suppliers is 1000 items to each supplier. In addition, the optimal allocation for emergency inventory among suppliers is 2000 items from supplier S[6] to warehouse W[2] (Figure7).The expected total cost for the Pre-positioning Inventory Model is $\$ 143,595.00$. There is onlya0.5\% chance to lose a portion of demand at the end of the cycle. In all of the scenarios with disruption in one supplier, and most of the scenarios with simultaneous disruptions in two suppliers, the allocation of the disrupted suppliersare completely covered by pre-positioned inventories in the warehouse.

Using the mitigation strategy of pre-positioning inventory, the solution shows the selection of the twomost reliable and expensive suppliers, and also the two least reliable and least expensive suppliers,in 
the supply base. Meanwhile, a warehouse in the region with medium reliability level was selected to be built to keep emergency inventory in case disruptions happen in suppliers and regions. Selection of the most and least expensive suppliers (most and least reliable) indicates that the model is making a balance between reliability and costs. Selection of the warehouse in the second region is minimizing the impact of regional disruptions by spreading entities in different regions, while also making a balance between transportation costs and loss costs. In addition, since emergency inventory fulfillment is a one-time process, the least expensive supplier was selected to satisfy the needs of the manufacturer for prepositioning emergency inventory.

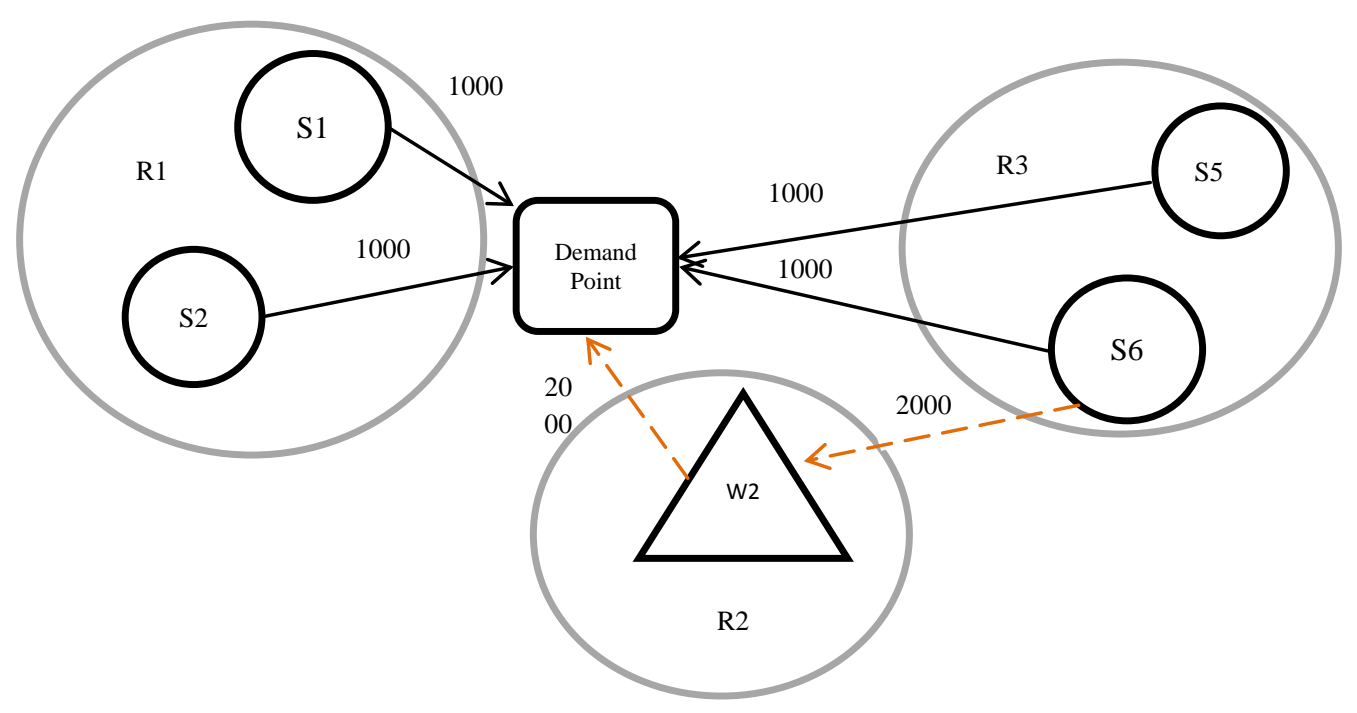

Figure 7.Solution for the Pre-positioning Inventory Model

Although the sourcing policy suggested by this model with 3 regions, 4 suppliers, and 1 warehouse, has more actorsand links and consequently more complexity than the General Model, which included only two regions, and 3 suppliers,the result showsa $8.2 \%$ reduction in expected total costs anda 8.3\% increase in service level. Using the strategy of pre-positioning inventory, the manufacturer would be able to satisfy the demand completely in all scenarios with a relatively high probability of occurrence (i.e., due to the disruption in one supplieror two suppliers).

\subsection{Backup Suppliers Model example}

The second disruption mitigation strategy usesbackup suppliers as redundant resources. We apply the following modifications to the firstexample. We assume that the manufacturer intends to select some suppliers as primary suppliers and some suppliers as secondary or backup suppliers to be used only during disruptions. We should recall that backup suppliers are also exposed to supplier and 
regionaldisruptions.We assume if one supplier is selected as the backup, it can use half of its entire capacity to produce emergency supplies. Table 4shows the backup contracting cost(we assume the backup contracting costs equal the warehouse building costs in the pre-positioning inventory model example), the unit cost in normal and disruption situations (unit cost in disruption is \$10 more than the normal unit cost for each supplier),the holding cost of each supplier (which is $20 \%$ ofnormal unit cost), and the emergency capacity.The pre-disruption budget is assumed to be $\$ 100,000$.

Table 4. Backup Suppliers Information

\begin{tabular}{|c|c|c|c|c|c|c|}
\hline & \multicolumn{2}{|c|}{ Region 1 } & \multicolumn{2}{c|}{ Region 2 } & \multicolumn{2}{c|}{ Region 3 } \\
\hline Suppliers & S[1] & S[2] & S[3] & S[4] & S[5] & S[6] \\
\hline Normal Cost (\$/item) & 25 & 22 & 20 & 15 & 12 & 10 \\
\hline Disruption Cost (\$/item) & 35 & 32 & 30 & 25 & 22 & 20 \\
\hline Holding Cost (\$/item) & 5 & 4.5 & 4 & 3 & 2.5 & 2 \\
\hline Emergency Capacity (items) & 1000 & 1250 & 1500 & 1750 & 2000 & 2250 \\
\hline Backup Contracting Cost (\$) & 5000 & 5000 & 5000 & 5000 & 5000 & 5000 \\
\hline
\end{tabular}

The optimal solution is selection of suppliers S[3] from region 2, and S[5] and S[6] from region 3 in the supply base as primary suppliers. Supplier S[1] and S[2] from region 1 and supplier S[4] from region 2 are selected as backup suppliers. The optimal allocation of primary suppliers is supplier S[3]: 825, S[5]: 1825, andS[6]: 1350.The optimal maximum emergency allocation of backup suppliers is: S[1]: 1000, S[2]: 1125 , and S[4]: 1575 (Figure8).Dashed arrows in Figure 8 show the maximum output of emergency items from backup suppliers in case of disruptions in primary suppliers.

The expected total cost for the backup suppliermodel is $\$ 127,838.00$. Based on the results, in all scenarios with disruption in one supplier and simultaneous disruptions in two suppliers, all of the allocations of the disrupted suppliersare covered by backup suppliers. There is onlya $0.74 \%$ chance of losing a portion of demand at the end of the cycle. When using the backup suppliers strategy with emergency inventory, in order to make a balance between costs and risks, the least expensiveand least reliable suppliers from the last region and one mid-expensive mid-reliable supplier from the second region are selected as primary ones. On the other hand, reliable and expensive suppliers are chosen as backup suppliers, in order to ensure that backup suppliers are available when primary ones are not.In some of the scenarios, when backup suppliers are supposed to deliver items, they themselves are disrupted and unable to deliver products. Therefore, we see more than one backup supplier in the backup supply base.The selection of suppliers from all regions is for the purpose of minimizing regional disruption impacts.

The numerical example shows a18.6\% reduction in the expected total cost,compared to the General Model. In addition, using this sourcing policy and its contingency plans will ensure that there is a99.26\% chance for the manufacturerto cover all the demand. The probability for loss of a portion of 
demand is reduced from $8.8 \%$ in the general model example to $0.75 \%$ in the backup suppliers model example.

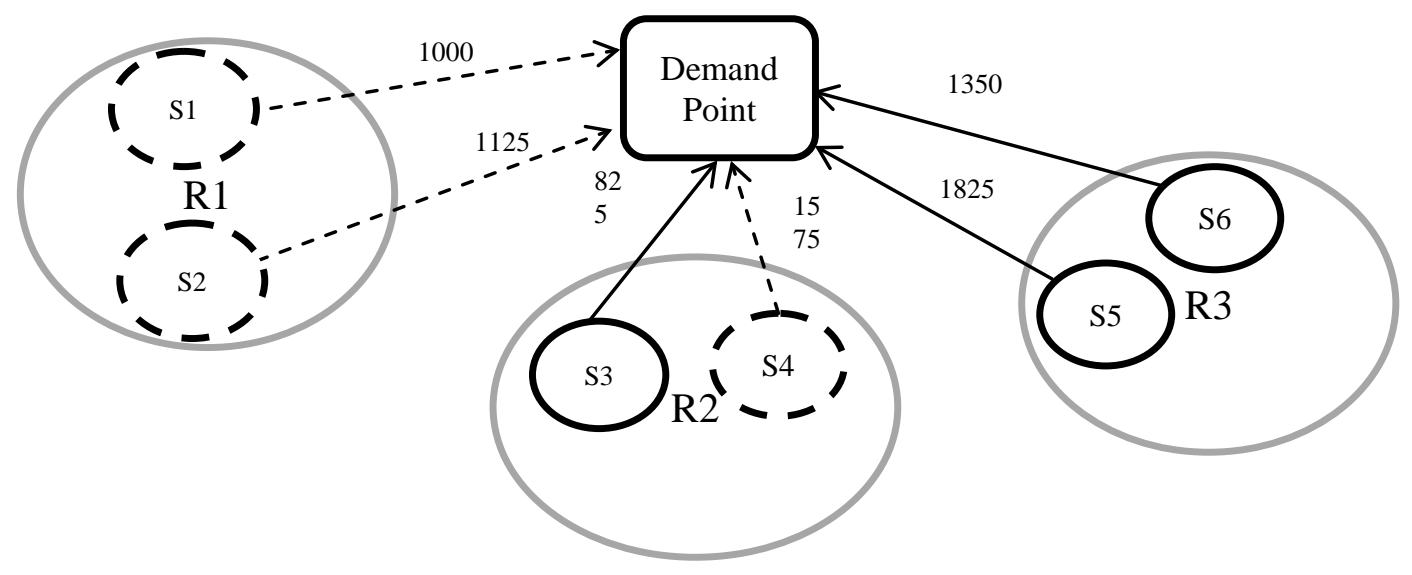

Figure 8. Solution for the Backup Suppliers Model

\subsection{Protected Suppliers Model example}

The third supply disruption mitigation strategy uses protection of suppliers as redundant resources. We assume that the manufacturer is interested in investment in suppliers to enhancetheir reliability. It is expected that the level of investment in the supplier is inversely related to its current level of reliability, i.e., the more unreliable a supplier is, the more supplier investment is needed.Note that disruption in a region causes unavailability of both protected and unprotected suppliers in that region. Table 5shows thedisruption probability, protection cost (which is assumed to be close in value to the backup contracting and warehouse building costs in the examples of thetwo previous models),normal and disruption unit cost, holding cost of each supplier (which is $20 \%$ of the normal unit price),and emergency capacity (which is the half of the normal capacity of each supplier). We assume the pre-disruption budget is $\$ 100,000$.

Table 5. Protected SuppliersInformation

\begin{tabular}{|c|c|c|c|c|c|c|}
\hline & \multicolumn{2}{|c|}{ Region 1 } & \multicolumn{2}{c|}{ Region2 } & \multicolumn{2}{c|}{ Region 3 } \\
\hline Suppliers & S[1] & S[2] & S[3] & S[4] & S[5] & S[6] \\
\hline Disruption Probability & $1 \%$ & $2 \%$ & $4 \%$ & $6 \%$ & $8 \%$ & $10 \%$ \\
\hline Protection Cost (\$) & 3000 & 4000 & 6000 & 8000 & 10000 & 12000 \\
\hline Normal Cost (\$/item) & 25 & 22 & 20 & 15 & 12 & 10 \\
\hline Disruption Cost (\$/item) & 35 & 32 & 30 & 25 & 22 & 20 \\
\hline Holding Cost (\$/item) & 5 & 4.5 & 4 & 3 & 2.5 & 2 \\
\hline Emergency Capacity (items) & 1000 & 1250 & 1500 & 1750 & 2000 & 2250 \\
\hline
\end{tabular}


The optimal solution is protecting suppliersS[4] and S[6], the least expensive suppliers of region 2 and 3, and selecting supplier S[2] as an unprotected supplier in the supply base. The optimal allocation is: S[2]: 500, S[4]: 1750, and S[6]: 1750 (Figure9). The number of emergency inventory to be prepositioned atprotected supplier S[4] is 1750, and S[6] is also1750.As shown in Figure 9, when a supplier or regional disruption makes suppliers in that region unavailable, the protected supplier in another regiontries to makeup the shortage. The expected total cost for the supplier protection model is $\$ 122,000.02$. There is a $0.09 \%$ chance of losing a portion of demand at the end of the cycle.

Using the supplier protection strategy with emergency inventory, selection of one supplier from each region is for the purpose of minimizing regional disruptions, as they are unavoidable even for protected suppliers. Although suppliersS[4] and S[6] have higher protection costs compared to the other suppliers in their regions and region 1, their lower purchasing costs justify their protection.In short, the result of this example shows that the most important factor that determines the suppliers to be selected and protected is unit cost, not reliability or risk. The result of this numerical example shows about a $22 \%$ reduction in the expected total cost compared to the General Model example. In addition, based on the results, using this sourcing policy and its contingency plans ensures that there is a $99.9 \%$ chance that the manufacturer experiences no losses. The results show that the probability for loss of a portion of demand is reduced from $8.8 \%$ in the General Model example to $0.01 \%$ in the Protected Suppliers Model example.

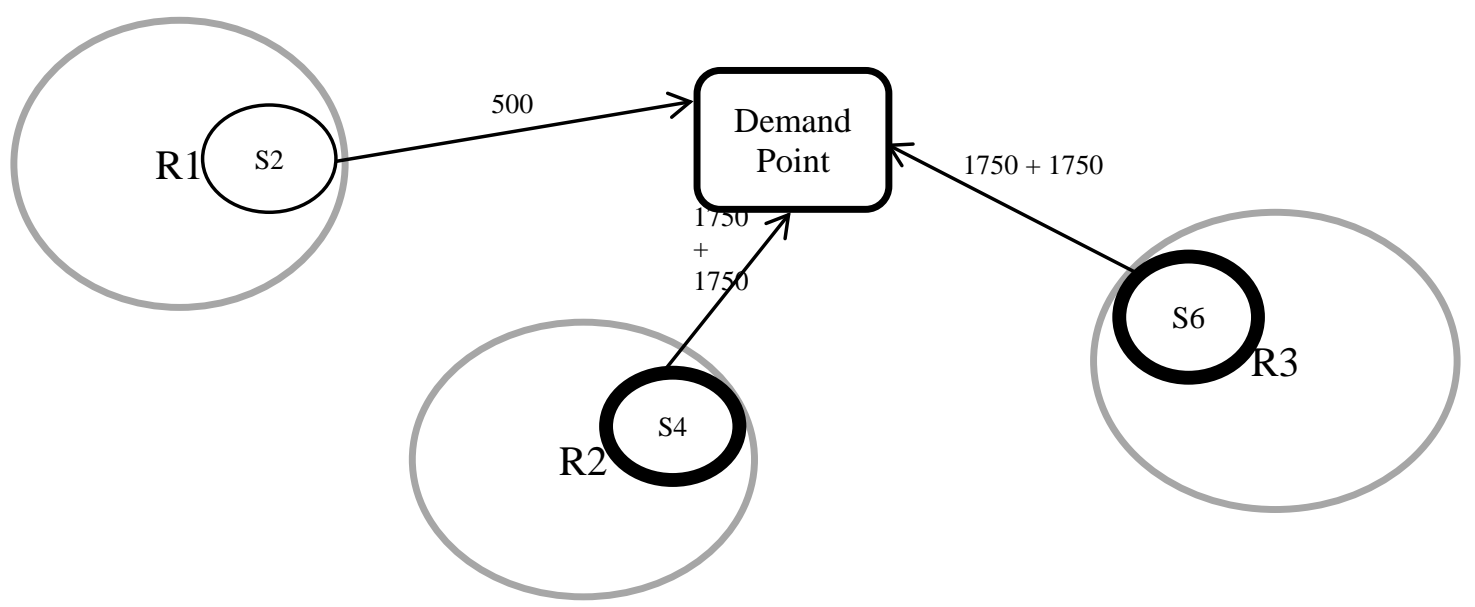

Figure 9. Solution for the Protected Suppliers Model

\subsection{Comparison among different disruption mitigation strategies}

We conducted a numerical example withthe General Model with only multi-sourcing strategy. We later conducted the same numerical example using each of our disruption mitigation strategies: the Pre-positioning Inventory Model, the Backup Suppliers Model, and the Protected Suppliers Model. Figure 
10 compares how the three disruption management strategies mitigated the effects of disruption in a supply chain.

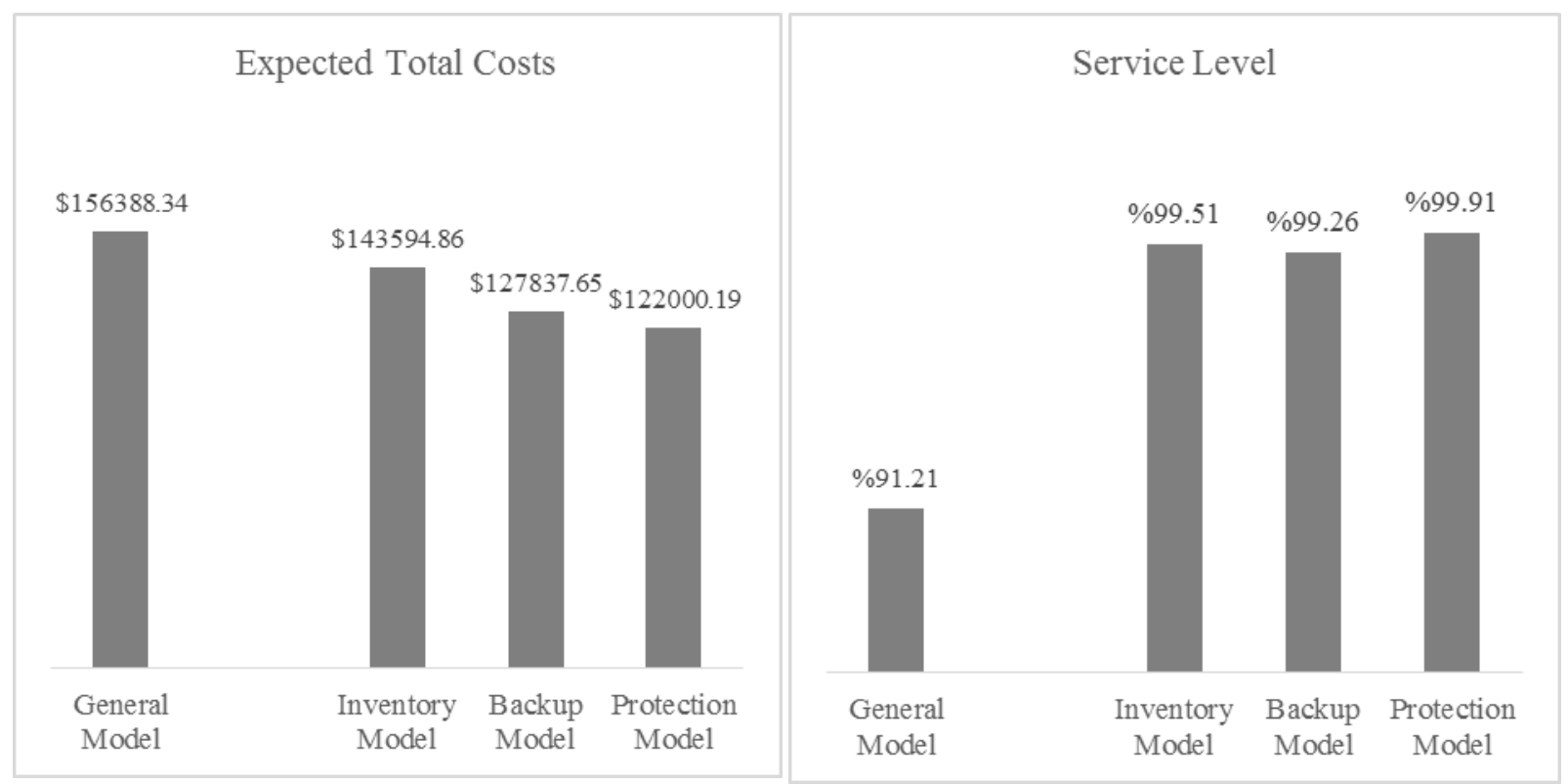

Figure 10. Comparison of expected total cost and loss probabilityof computational examples of each strategy and of the General Model

As mentioned by Chopra and Sodhi (2014), surveys have shown that there is a general belief among managers that risk reduction requires supplychaincapabilityinvestments that do not appear to be cost-effective in most cases. However,our resultsshow that disruption mitigation strategies not only protect the supply chain against disruptions by maximizing the service level (defined as the probability of zero loss to the manufacturer (Meena et al., 2011)), they also reduce the expected total costs of the supply chain.In our example,implementing any of the three disruption mitigation strategies (broadly considered as adding redundancy)is superior to having no strategy. Based on our computational example, it is clear that even though the likelihood of disruption could be very small, the financial consequences are significant. To minimize the negative impactof scenarios with disruptions, the contingency plans that our models suggested include switching demand from disrupted suppliers to pre-positioned warehouses,backup suppliers, and protected suppliers. However, due to regional disruptions, dependence of available suppliers on disrupted ones, the limitations on pre-disruption budgets, and the capacity of 
different entities in the supply chain, a portion of demand may remain unsatisfied in some scenarios, especially with concurrent disruptions in more than one supplier and aregion.

Overall, our example and models show that even though a manufacturer incurs additional costs by regionalizing its supply base and working with multiple suppliers, building warehouses, contracting with backup suppliers, protecting and fortifying suppliers, and pre-positioning emergency inventory, the firm would benefit from these investments when supplies and environmental risks disrupt the supply chain. This suggests that implementation of any supply mitigation strategy (pre-positioned inventory warehouses, backup suppliers,or protected suppliers) reducesthe expected total costs and increases service level, when we incorporate contingency plans into the supplier selection and demand allocation decisions. The manufacturer should also know that suppliers do not work in isolation, and disruption in one may impact the rest of the suppliers. We showed how taking this factor into account led to the spread of allocation among more entities.

\section{Sensitivity Analyses}

In this section, a number of sensitivity analyses are conducted on several model parameters to understand the behavior of the model in different circumstances and make the findings more robust.

\subsection{Sensitivity analysis of reliability and dependence of suppliers and reliability of regions}

In this section, we conduct three sensitivity analyses to examine howthe final results can be affected by the type of disruption (supplier or environmental disruption), the reliability of suppliers and regions, and the dependence of suppliers on one another. First, we analyze the reliability of suppliersS[1] and S[6] as the most and least reliable suppliers on all the four models. We define six levels of reliability for these suppliers from high reliability to low reliability,with disruption probabilitiesset to $1 \%, 2 \%, 4 \%, 6 \%, 8 \%$, or $10 \%$. We aim to examine the effects of these changes on the final result of each model. In the second part, we analyze how suppliers' dependence on one another will change the selection and allocation of suppliers. With 6 suppliers, a great number of alternatives can be proposed.For the sake of space, we consider only one alternative setting, which we call setting $A^{*}$. According to setting $A^{*}$, a disruption in suppliers S[1] and S[2] separately reduces the capacity of suppliers S[3] and S[4] by 50\%; a disruption in suppliers S[3] and S[4] separately reduces the capacity of suppliers S[5] and S[6] by 50\%; finally, a disruption in supplier S[6] zeros the capacity of suppliers S[1] and S[2]. Again, these dependencies might be for any reason, including but not limited to sharing common second-tier suppliers. With these changes, suppliers S[1] and S[2], which were the most reliable suppliers (least disruption probability), will be the most unreliable ones; since they would be unavailable in all scenarios where S[6] is disrupted. Disruption in S[5] would not impact any other suppliers. Therefore S[5] is an attractive choice. S[3] and S[4] are now the most reliable suppliers even though their capacity will be cut in half when a disruption hits either of $\mathrm{S}[1]$ or $\mathrm{S}[2]$. We will see how these changes will affect the final result of each model in this setting. 
Finally, we will examinein more detail the effect of changes inregions' reliabilities on the final results. For this purpose, we first separately set the regional disruption of each of the three regions to 0 , representing a highly reliable region; then we separately set the disruption probability of each region to $10 \%$, representing a highly unreliable region. Finally we set the disruption probability of all three regions to 0 and $10 \%$. We will discuss results of each analysis on each of the four models respectively.

\subsubsection{General Model: Multi-sourcing strategy.}

The result of changes in the disruption probability of suppliersS[1] and S[6] are shown in Figure 11. According to this figure, suppliers are in the supply base when they are highly reliable; otherwise, they are out. When supplier S[1]'s reliability drops, a fourth supplier is added to the supply chain to increase the reliability of the supply base. Since a disruption in S[1] reduces the capacity of S[2] by 50\%, supplier S[3] gets more allocation (instead of S[2]) as the reliability of S[1] drops. When reliability of supplier S[6] drops, since there are two reliable suppliers in the supply base (S[1] and S[2]), the model adds a third supplier for a very small portion of demand. The third supplier is S[3] and not S[4] or S[5], since $20 \%$ of S[4]'s and 50\% of S[5]'s capacity depend on S[3]'s availability. The analysis shows that the reliability of one supplier is a very important factor that affects the selection and allocation of all suppliers.

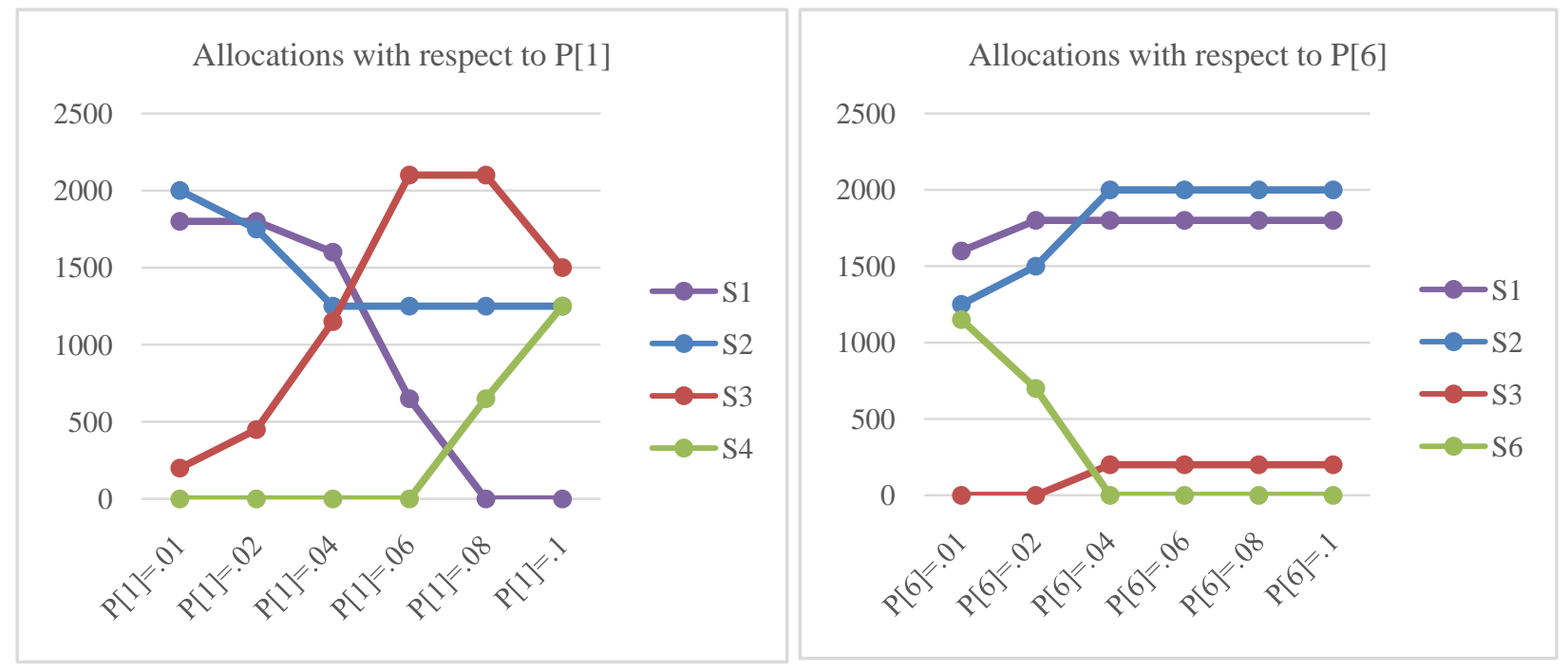

Figure 11. Suppliers' allocation with respect to changes in disruption probability of supplier S[1] and S[6]

Now, we analyze the dependence of suppliers on one another. Considering the setting $A^{*}$, the allocation result changes from S[1]: 2000, S[2]:1800, and S[3]:200 in the numerical example to $S[3]: 2250$, and $S[4]: 1750$ in the setting $A^{*}$. As expected, the dependence of suppliersS[1] and S[2] on unreliable supplier S[6] led to their elimination from the supply base. Therefore, the 
model has chosen second region suppliers, which are now the most reliable ones,to minimize the impact of disruptions.

Finally, we discuss the analyses on regions' reliabilities. The results are shown in Table 6. The first three columns show the disruption probability in each region, and the next columns show the allocation of each supplier in each setting. The first three rows represent one highly reliable region;the second three rows represent one highly unreliable region; the next row represents three reliable regions; and the last row representsthree unreliable regions. As shown in Table 6, highly reliable suppliers in the first region are in the supply base most of the time, unless the first region is highly unreliable; in that case, these suppliers are replaced by second region suppliers. Although third region suppliers offer inexpensive prices, they are not selected in the supply base in any of the settings which is additional evidence that supports the importance of reliability compared to costs for a multi-sourcing strategy. The analysis of this section highlights the importance of the interaction between the reliability of suppliers and regions on sourcing decisions in a multi-sourcing setting.

Table 6. Sensitivity Analysis of Regions’ Reliabilities in the General Model Example

\begin{tabular}{|c|c|c|c|c|c|c|c|c|}
\hline & & & \multicolumn{2}{c|}{ Region1 } & \multicolumn{2}{c|}{ Region2 } & \multicolumn{2}{c|}{ Region3 } \\
\hline $\mathrm{P} *[1]$ & $\mathrm{P} *[2]$ & $\mathrm{P} *[3]$ & $\mathrm{S}[1]$ & $\mathrm{S}[2]$ & $\mathrm{S}[3]$ & $\mathrm{S}[4]$ & $\mathrm{S}[5]$ & $\mathrm{S}[6]$ \\
\hline $0 \%$ & $1 \%$ & $2 \%$ & 1800 & 2000 & 200 & - & - & - \\
\hline $0.5 \%$ & $0 \%$ & $2 \%$ & 1800 & 1750 & 450 & - & - & - \\
\hline $0.5 \%$ & $1 \%$ & $0 \%$ & 1800 & 2000 & 200 & - & - & - \\
\hline \multicolumn{10}{|c|}{} \\
\hline $10 \%$ & $1 \%$ & $2 \%$ & - & - & 2100 & 1900 & - & - \\
\hline $0.5 \%$ & $10 \%$ & $2 \%$ & 2000 & 2000 & - & - & - & - \\
\hline $0.5 \%$ & $1 \%$ & $10 \%$ & 1800 & 2000 & 200 & - & - & - \\
\hline \multicolumn{10}{|c|}{} \\
\hline $0 \%$ & $0 \%$ & $0 \%$ & 1800 & 1750 & 450 & - & - & - \\
\hline $10 \%$ & $10 \%$ & $10 \%$ & 1800 & 2000 & 200 & - & - & - \\
\hline
\end{tabular}

\subsubsection{Pre-positioning Inventory Model example}

The result of a sensitivity analysis of suppliersS[1]'s and S[6]'sreliabilities in the Pre-positioning Inventory Model example is shown in Figure 12.According to Figure 12, for supplier S[1] to be in the supply base, its disruption probability should be less than $1 \%$. Otherwise, not only would it be replaced by supplier S[4], but also since the reliability of the supply base drops with this arrangement, a second warehouse is also added to make the firm more responsive to disruption. Supplier S[6]'s reliability does not significantly change the final result. The only change that we see is that its allocation increases with its reliability. But because of its cost-efficiency, it is still kept in the supply base even when it is 
unreliable, to make a balance between costs and risks. The interesting finding of this analysis is that in all of the settings, the model has chosen at least one entity from each region, to spread the supply sources and minimize the impact of environmental disruptions.

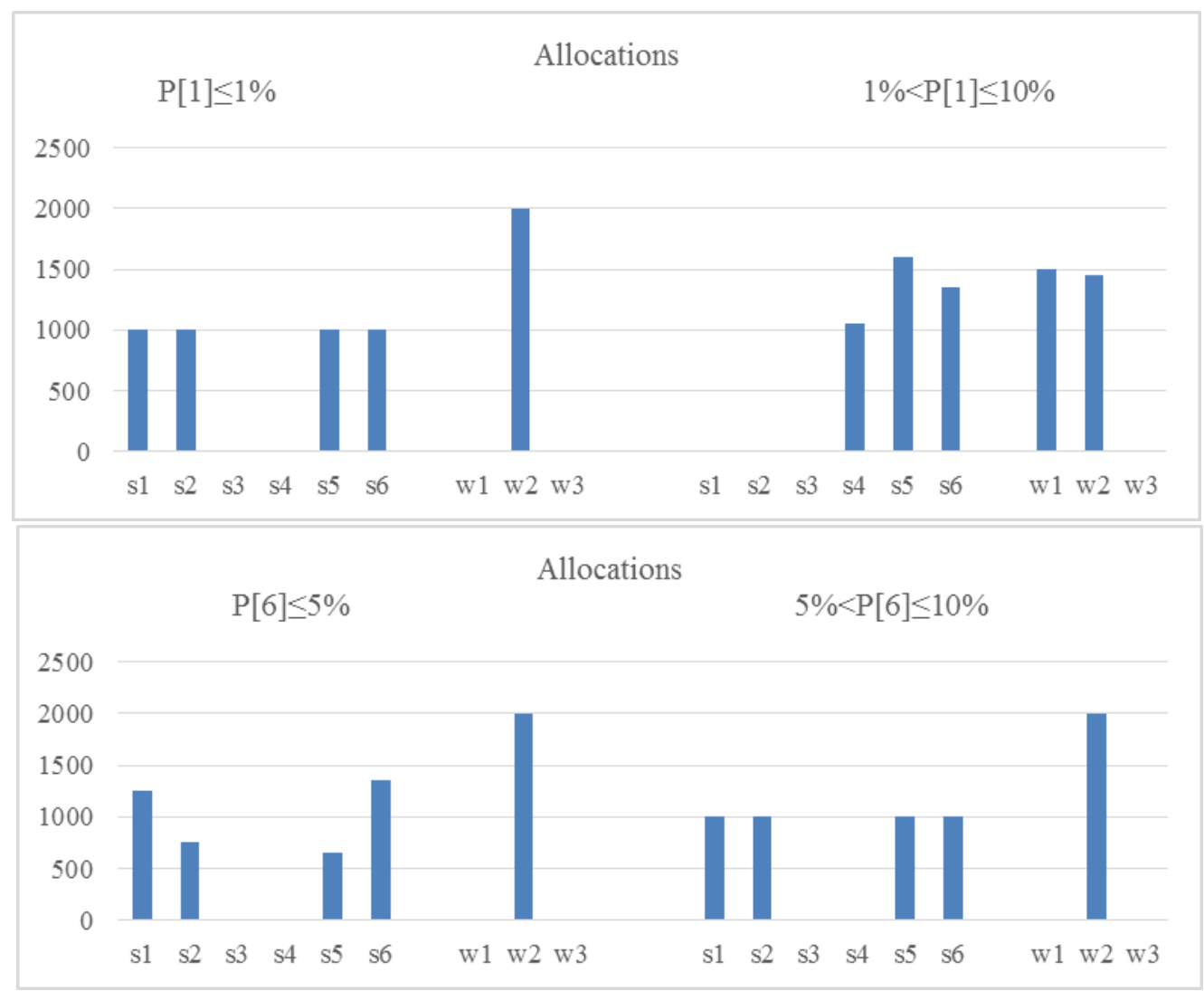

Figure 12. Suppliers' allocation with respect to changes in disruption probability of supplier S[1] and $S[6]$

The analysis of suppliers' dependence is now discussed. The setting of $A^{*}$, will change the selection and allocations from $\mathrm{S}[1]=\mathrm{S}[2]=\mathrm{S}[5]=\mathrm{S}[6]: 1000$, and $\mathrm{W}[2]: 2000$ in our numerical example to S[3]:750, S[4]:1750, S[5]:750, S[6]:750, W[1]:1500, and W[3]:1750. Similar to the General Model analysis, we see that suppliersS[1] and S[2] are removed from the supply base, because their high dependence on S[6] makes them highly unreliable. Most of the allocation goes to S[3] and S[4], which are the most reliable suppliers in the current setting. To reduce the impact of regional disruption in this 
region, two warehouses are chosen in the other two regions in conjunction with two third-region suppliers. The model has diversified the supply base to reduce the impact of disruptions and suppliers' dependence on one another.

Next, we present sensitivity analyses of regions' reliabilities in the Pre-positioning Inventory Model. The results are shown in Table 7. The format of Table 7 is similar to the Table 6 format. According to this table, when one region is highly reliable, suppliers of this region are selected in the supply base, and the warehouse also should be built in this region. Suppliers from other regions may also be selected to increase responsiveness to supplier disruptions. In case of having three reliable regions, a third-region warehouse is selected, since more items can be stored in it with the same building costs. When one region is highly unreliable, two warehouses should be built in the other two regions. Since these warehouses increase the reliability of the supply base, the least expensive suppliers are selected as primary sources of supplies. In the case of three unreliable regions, demand is spread almost evenly across regions to increase responsiveness and minimize lack of supplies in case of regional disruptions. The analysis of this section shows how the reliabilities of regions are determinant factors on the selection of the warehouses and the development of contingency plans with respect to pre-positioned inventory.

Table 7. Sensitivity Analysis of Region Reliabilities in the Pre-Positioning Inventory Model Example

\begin{tabular}{|c|c|c|c|c|c|c|c|c|c|c|c|}
\hline$\gamma$ & 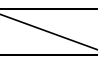 & 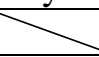 & \multicolumn{2}{|c|}{ Region1 } & \multicolumn{2}{|c|}{ Region2 } & \multicolumn{2}{|c|}{ Region3 } & Region1 & Region2 & Region3 \\
\hline $\mathrm{P} *[1]$ & $\mathrm{P} *[2]$ & $\mathrm{P} *[3]$ & $\mathrm{S}[1]$ & $\mathrm{S}[2]$ & $\mathrm{S}[3]$ & $\mathrm{S}[4]$ & $\mathrm{S}[5]$ & $S[6]$ & $\mathrm{W}[1]$ & $\mathrm{W}[2]$ & $W[3]$ \\
\hline $0 \%$ & $1 \%$ & $2 \%$ & 1000 & 750 & - & 750 & 750 & 750 & 1500 & - & - \\
\hline $0.5 \%$ & $0 \%$ & $2 \%$ & - & - & 1000 & 1000 & 1000 & 1000 & - & 2000 & - \\
\hline $0.5 \%$ & $1 \%$ & $0 \%$ & - & 250 & - & 1250 & 1250 & 1250 & - & - & 2500 \\
\hline & & & & & & & & & & & \\
\hline $10 \%$ & $1 \%$ & $2 \%$ & - & 250 & - & 1750 & 1500 & 500 & - & 2000 & 2500 \\
\hline $0.5 \%$ & $10 \%$ & $2 \%$ & - & 750 & - & 1750 & 150 & 1350 & 1500 & - & 2500 \\
\hline $0.5 \%$ & $1 \%$ & $10 \%$ & - & 525 & - & 525 & 1600 & 1350 & 1500 & 1975 & - \\
\hline & & & & & & & & & & & \\
\hline $0 \%$ & $0 \%$ & $0 \%$ & - & - & 250 & 1250 & 1250 & 1250 & - & - & 2000 \\
\hline $10 \%$ & $10 \%$ & $10 \%$ & 700 & 700 & 600 & 700 & 800 & 500 & - & 2000 & 2500 \\
\hline
\end{tabular}

\subsubsection{Backup Suppliers Model example}

Figure 13 shows the result of a sensitivity analysis of suppliers S[1]'s and S[6]'sreliabilities in the Backup Suppliers Model example. In Figure 13, the figure on the left represents the changes in allocation of suppliers S[3], S[5], and S[6] as primary suppliers. In all of the settings, suppliersS[1], S[2], and S[4] are chosen as backup suppliers and their allocations are almost fixed. But as we see, when supplier S[1] is less reliable, which makes supplier S[2] also less reliable (because 50\% of S[2]'s capacity depends on a non-disrupted S[1]), a portion of demand allocation of supplier S[5] goes to a more reliable S[3] to increase the reliability of the supply base and consequently decrease the likelihood of a need for backup resources. The right figure shows the changes in allocation of suppliers S[3], S[4], S[5], and S[6] as 
primary suppliers with respect to changes in the reliability of supplier S[6]. According to this figure, when S[6] is reliable, S[4], S[5], and S[6] are primary suppliers and all others are backup suppliers. But when S[6]'s reliability drops, S[4] is replaced by a more reliable supplier S[3] to increase the reliability of the supply base. The analysis of this section shows how the model tries to keep reliability up and costs down, by adding more reliable suppliers when reliability of current suppliers drops and also keeping less expensive suppliers of the third region in the supply base.
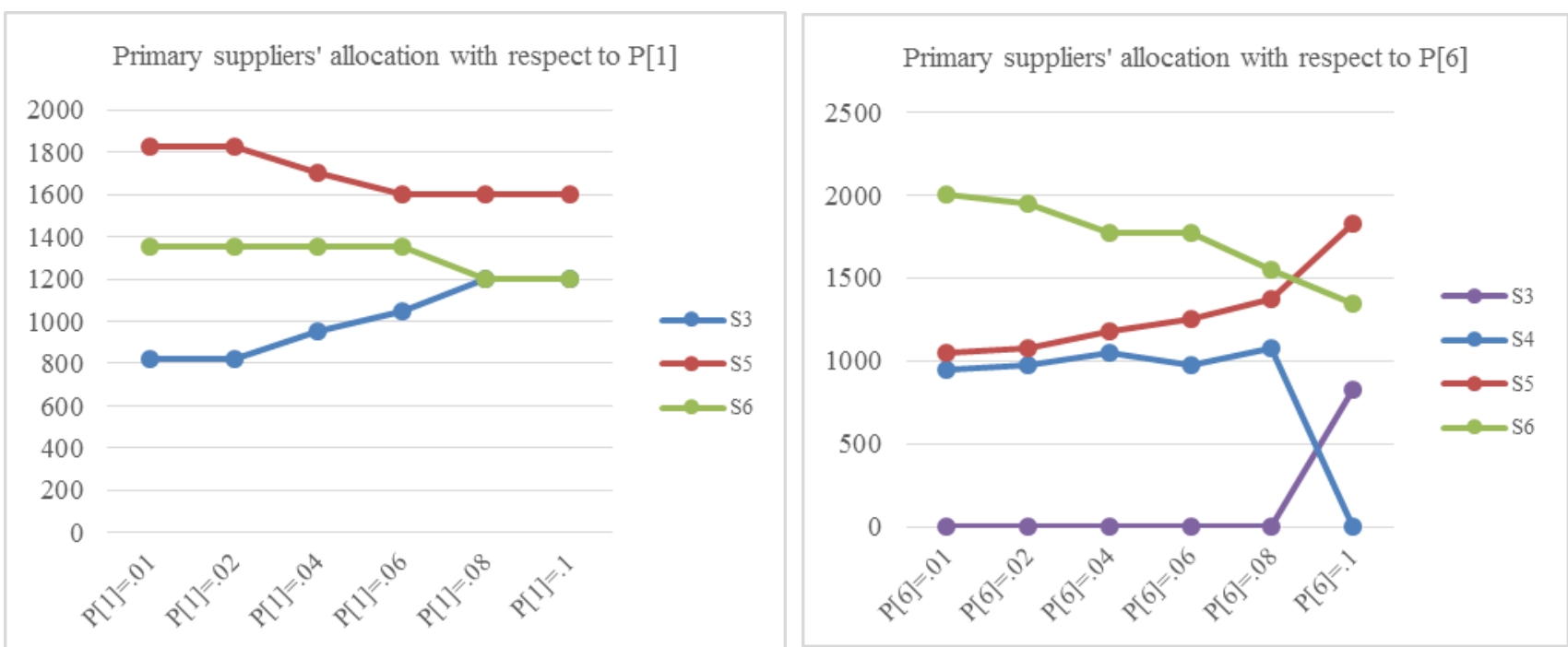

Figure 13. Primary suppliers' allocation with respect to changes in the disruption probabilities of suppliersS[1] and S[6]

We now discuss the analysis of suppliers' dependence. The setting of $A^{*}$ will change the selection and allocations from primary suppliers: S[3]:825, S[5]:1825, and S[6]:1350; backup suppliers: $\mathrm{S}[1]: 1000, \mathrm{~S}[2]: 1125$, and S[4]:1575 in our numerical example to primary suppliers: S[4]:1750, S[5]:2000, and S[6]: 250; backup suppliers: S[1]:1000, S[2]:1250, and S[3]:1500. Compared to our numerical example results, here we see supplier S[3] and S[4] switch their positions in the primary and backup supply bases. The allocation of S[5] increases and S[6] drops. This change is due to the fact that a disruption in S[6] will make backup suppliers S[1] and S[2] unavailable. Therefore, only S[3] remains to make up the lost allocation of S[6]. For this reason, the allocation of S[6] has dropped to enable S[3] to satisfy the demand when S[6] is disrupted. In contrast, a disruption in supplier S[5] does not impact any other suppliers, which means all backup sources would be available to make up the loss of this supplier. 
Therefore,S[5] has received a higher allocation. The result shows the importance of considering the dependence of suppliers on one another when choosing between backup and primary suppliers.

Finally, the result of the analyses of regions' reliabilities is presented in Table 8. To distinguish backup suppliers from primary ones, we have used a grey background for the allocation of backup suppliers in different settings.We see that the arrangement of suppliers as primary and backup suppliers does not change when one region has zero disruption probability; but the allocations (mostly for primary suppliers) change. When one region is highly unreliable, the number of backup suppliers may increase. So the firm allocates more items to fewer suppliers from other regions, but makes sure there are enough backup sources to address lack of supplies in disruptions. When all regions are reliable, the cost factor determines which suppliers serve as primary sources; however, when all regions are unreliable, the reliability factor determines primary suppliers. The general finding of this analysis is that in almost all cases, less expensive suppliers are chosen as primary suppliers to reduce the cost in normal situations, and more reliable and expensive suppliers are chosen as backup suppliers to ensure the consistency of material flow when primary sources are unavailable.

Table 8. Sensitivity Analysis of Regions’ Reliabilities in the Backup Supplier Model Example

\begin{tabular}{|c|c|c|c|c|c|c|c|c|}
\hline \multicolumn{10}{|c|}{} & \multicolumn{1}{c|}{ Region1 } & \multicolumn{2}{c|}{ Region2 } & \multicolumn{2}{c|}{ Region3 } \\
\hline $\mathrm{P}^{*}[1]$ & $\mathrm{P}^{*}[2]$ & $\mathrm{P} *[3]$ & $\mathrm{S}[1]$ & $\mathrm{S}[2]$ & $\mathrm{S}[3]$ & $\mathrm{S}[4]$ & $\mathrm{S}[5]$ & $\mathrm{S}[6]$ \\
\hline $0 \%$ & $1 \%$ & $2 \%$ & 1000 & 1000 & 1050 & 975 & 1475 & 1550 \\
\hline $0.5 \%$ & $0 \%$ & $2 \%$ & 900 & 1000 & 1050 & 1550 & 1150 & 1300 \\
\hline $0.5 \%$ & $1 \%$ & $0 \%$ & 1000 & 1125 & 1050 & 825 & 1625 & 1550 \\
\hline \multicolumn{10}{|c|}{} \\
\hline $10 \%$ & $1 \%$ & $2 \%$ & 1000 & 1000 & 1500 & 1750 & 2000 & 2000 \\
\hline $0.5 \%$ & $10 \%$ & $2 \%$ & 1000 & 1250 & 950 & 1575 & 2000 & 2000 \\
\hline $0.5 \%$ & $1 \%$ & $10 \%$ & 1475 & 1475 & 1050 & 1575 & 1050 & 1475 \\
\hline \multicolumn{10}{|c|}{} \\
\hline $0 \%$ & $0 \%$ & $0 \%$ & 1000 & 900 & 825 & 1275 & 1375 & 1350 \\
\hline $10 \%$ & $10 \%$ & $10 \%$ & 1900 & 1250 & 2100 & 1750 & 1750 & 2250 \\
\hline
\end{tabular}

\subsubsection{Protected Supplier Model example}

The result of the sensitivity analysis on supplier S[1]'s reliability in the protected suppliers model example doesn't show significant changes. This means that regardless of the reliability of this supplier, with the current set of parameters, suppliersS[4], and S[6] are going to be protected. But the result of the analysis on supplier S[6]'s reliability, which is shown in Figure 14, shows that when this supplier is highly unreliable, it is going to be protected in conjunction with S[4], the less expensive supplier of the second region. Supplier S[2] is also in the supply base, to increase responsiveness against regional disruptions. When supplier S[6] becomes more reliable, then having a reliable and inexpensive supplier justifies its selection in the supply base with no protection. In this case, the less expensive supplier of the second region is chosen to be protected against supplier disruption, and suppliersS[5] and S[6] are chosen 
as unprotected suppliers in the supply base. We see that the cost factor determines the suppliers to be protected and the suppliers to be chosen next to the protected suppliers in the supply base, as the reliability of the supply base would become high enough when having a protected supplier with zero disruption probability.

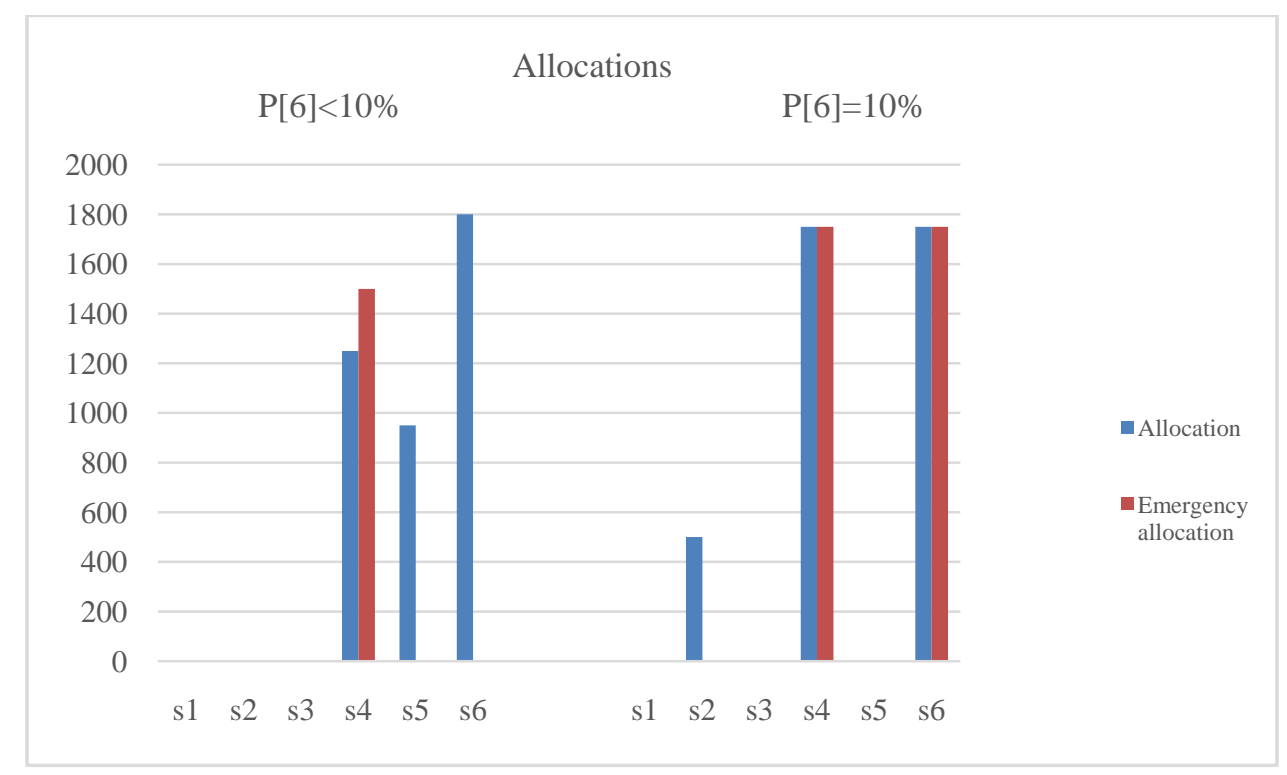

Figure 14. Suppliers' allocation with respect to changes in disruption probability of S[6].

Next, we discuss the suppliers' dependence analysis. Using the setting $A^{*}$ for dependence parameters, the only change in the result compared to the numerical example is that supplier $S[2]$ in the numerical example result is replaced by supplier S[5], since other suppliers are immune with respect to disruptions in this supplier. Suppliers S[4] and S[6] are again protected, but portions of their normal allocation are transferred to supplier S[5]. This analysis highlights the importance of how suppliers' interdependence influences the decisions regarding supplier selection, protection, and allocation.

Finally, we present the result of analyses of regions' reliabilitiesin Table 9. In Table 9, protected suppliers are distinguished by their grey cells. The number in parentheses after their allocation represents the allocation of emergency items for each protected supplier. According to this table, when highly reliable regions exist, one protected supplier from the second or third region who offers lower prices is chosen. When the third region is highly reliable, the selection of its two suppliers and protecting the less expensive one suffices. When one or more unreliable regions exist, the number of protected suppliers increases, and the demand is dispersed among more entities in different regions to increase the responsiveness of firms to highly likely regional disruptions. We observe four protected suppliers in the last row. The analysis of this section emphasizes the importance of regions' reliabilities (since protected 
suppliers are only exposed to regional disruptions) and the cost factor's influence on the decisions regarding which suppliers to protect and how many emergency items to be stored in protected suppliers. 
Table 9. Sensitivity Analysis of Region Reliabilities in the Supplier Protection Model Example

\begin{tabular}{|c|c|c|c|c|c|c|c|c|}
\hline$\gamma$ & $\gamma$ & $x^{2}$ & \multicolumn{2}{|c|}{ Region1 } & \multicolumn{2}{|c|}{ Region2 } & \multicolumn{2}{|c|}{ Region3 } \\
\hline $\mathrm{P} *[1]$ & $\mathrm{P} *[2]$ & $\mathrm{P} *[3]$ & $S[1]$ & $S[2]$ & $\mathrm{S}$ [3] & $\mathrm{S}[4]$ & $\mathrm{S}[5]$ & $\mathrm{S}[6]$ \\
\hline $0 \%$ & $1 \%$ & $2 \%$ & 0 & 500 & 0 & $1750(1750)$ & 0 & $1750(1750)$ \\
\hline $0.5 \%$ & $0 \%$ & $2 \%$ & 0 & 500 & 0 & $1750(1750)$ & 625 & 1125 \\
\hline $0.5 \%$ & $1 \%$ & $0 \%$ & 0 & 0 & 0 & 0 & 1750 & $2250(1750)$ \\
\hline $10 \%$ & $1 \%$ & $2 \%$ & 0 & 0 & 500 & 1750(1750) & 625 & 1750(2250) \\
\hline $0.5 \%$ & $10 \%$ & $2 \%$ & $500(1000)$ & $1250(1250)$ & 0 & 0 & 0 & $2250(2250)$ \\
\hline $0.5 \%$ & $1 \%$ & $10 \%$ & 0 & $625(1250)$ & 0 & $1250(1650)$ & 1000 & 1125 \\
\hline $0 \%$ & $0 \%$ & $0 \%$ & 0 & 0 & 0 & 0 & 1750 & $2250(1750)$ \\
\hline $10 \%$ & $10 \%$ & $10 \%$ & $250(1000)$ & 1250(1250) & 0 & $750(1750)$ & 0 & $1750(2250)$ \\
\hline
\end{tabular}

\subsection{Sensitivity analysis of fixed cost of capability development}

Since the result of our numerical example highly depends on the parameter values, here we investigate the effect of changes in the values that we assigned for the pre-disruption capability development in the final result of the three SCRM strategies.

\subsubsection{Pre-positioning Inventory Model example}

We now change the fixed cost of building the warehouses to see how the result will change with respect to this pre-disruption investment.We set the fixed warehouse building cost $\left(\mathrm{M}_{\mathrm{w}}\right)$ to $\$ 1000, \$ 5000$, and \$20000 (1, 5, and 20 times the fixed cost of adding one more supplier into the supply base). The selection and allocation results are shown in Figure 15 (We also set $\mathrm{M}_{\mathrm{w}}=\$ 10000$ and got the same result as $\left.\mathrm{M}_{\mathrm{w}}=\$ 5000\right)$.

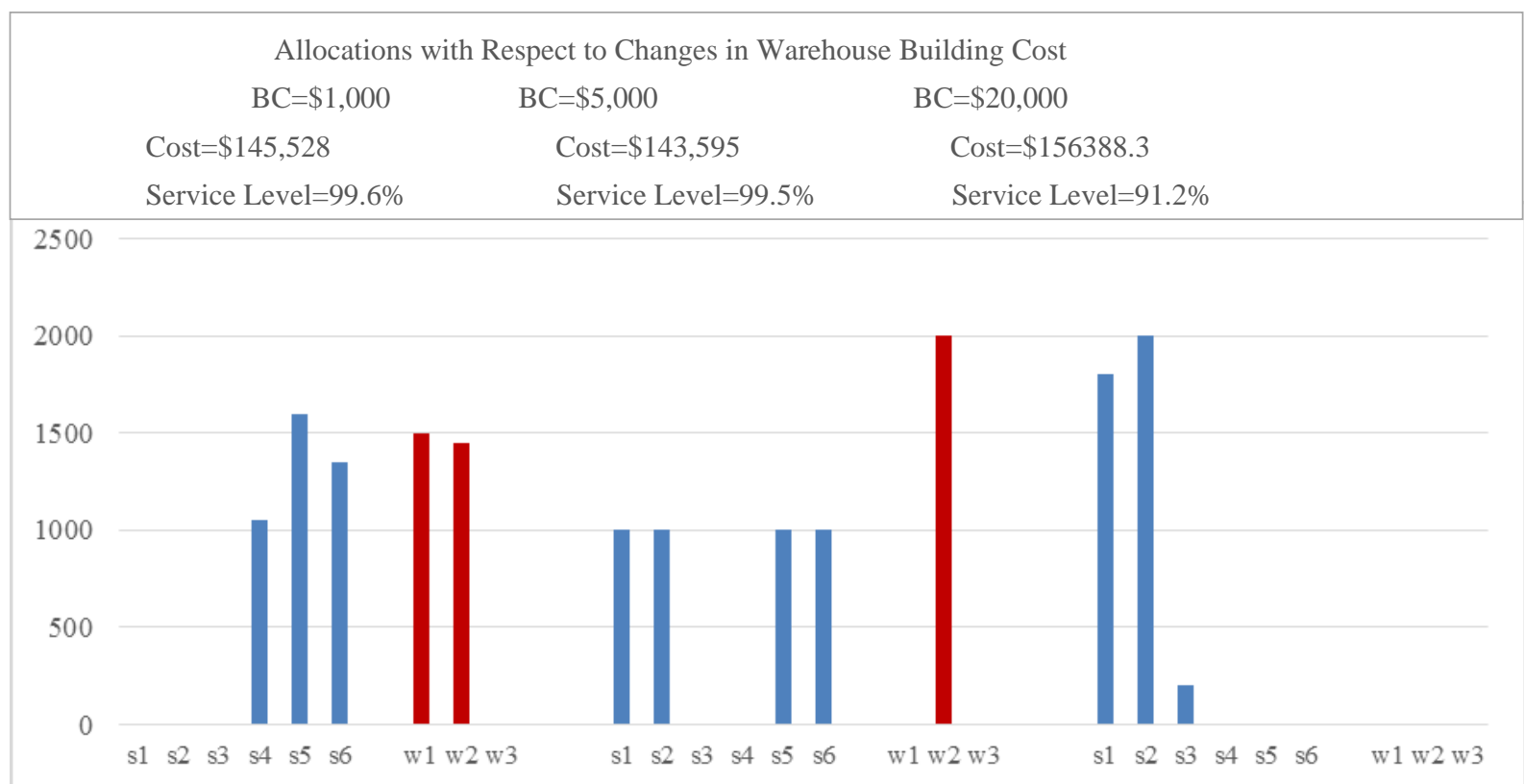

Figure 15. Solution of Pre-Positioning Inventory Model with respect to warehouse building cost 
We observe that when the cost of building warehouses is very low, the model chooses two warehouses in more reliable regions (even though their capacities are lower). Since the reliability increases by adding two warehouses, inexpensive and unreliable suppliers of the third region are added to the supply base. When the warehouse building cost increases, the number of warehouses is reduced to one, and ultimately when there is no justification for such an investment, the model opts not to build a warehouse and relies only ona multi-sourcing strategy. We also see how the model chooses different entities from different regions to minimize the impact of environmental disruptions. Expected total cost is higher on the first run with 2 warehouses, even though it is less costly to build warehouses.As expected, service level increases when there is more investment in inventories and disruption mitigation resources.

\subsubsection{Backup Suppliers Model example}

We conduct the same analysis here. We set the backup contracting cost $\left(\mathrm{G}_{\mathrm{h}}\right)$ for supplier $h$ equal to $\$ 1000, \$ 5000, \$ 10000$, and $\$ 20000$ to see how the result will change with respect to these changes.

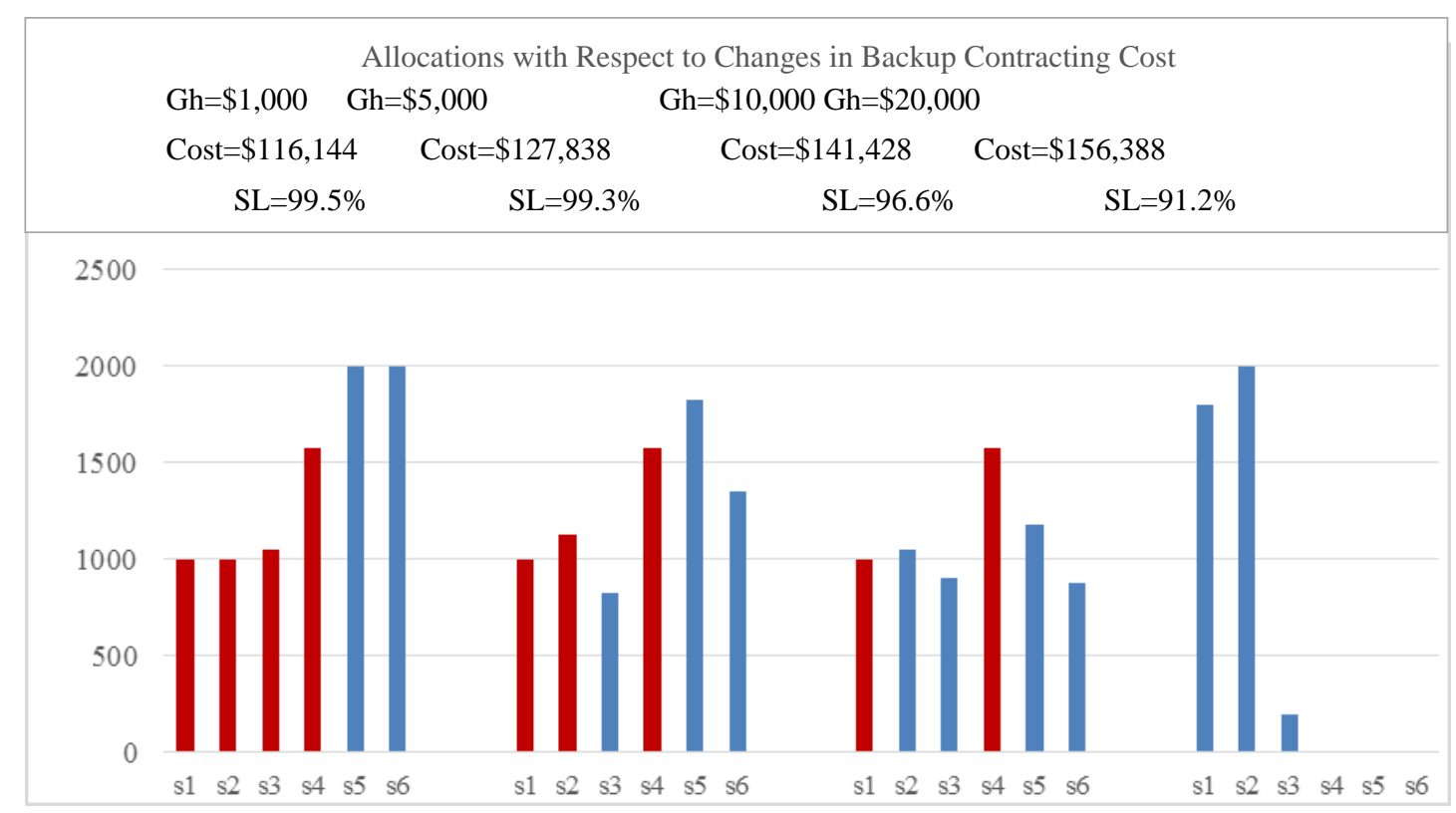

The results are shown in Figure 16.

Figure 16. Solution of Backup Suppliers Model with Respect to Backup Contracting Cost

We observe that when backup contracting cost is low, more suppliers are chosen as backup suppliers. As concluded before, the reliability factor determines backup suppliers,and the cost factor determines primary ones. As the backup contracting cost increases, the suppliers move from the backup supply base to the primary one, until investment in backup suppliers can't be justified. SuppliersS[1] and S[4] represent the ultimate backup sources when contracting cost is high. The model diversifies the supply base to reduce the impact of environmental disruptions. Interestingly, we observe that the highest service level is accompanied by the lowest costs. In general,increasing contracting costs leads to 
investment in fewer backup sources, more susceptibility to disruptions, and ultimately a lower service level.

\subsubsection{Supplier Protection Model}

The protection cost $\left(G_{h}\right)$ was assumed to be different across different suppliers and have an inverse relationship with the reliability of suppliers in our numerical example. In this section, we increase the protection cost of a supplier by $\$ 10000$, one after another, starting from the last supplier that was chosen as the main protected supplier in our numerical example. The result of this analysis is shown in Table 10. The first column shows the protection cost of suppliers in a row vector. The next columns represent the allocations, costs, and service level in that setting. Also, the first row represents the numerical example setting and solution, and succeeding rows represent $\$ 10000$ increases in the protection costs of suppliers, one after another. Grey cells represent protected suppliers, and the number in parentheses after their allocations represents their allocation of emergency items.

Table 10. Sensitivity Analysis of Protection Cost $\left(\mathrm{G}_{\mathrm{h}}\right)$ in the Supplier Protection Model Example

\begin{tabular}{|c|c|c|c|c|c|c|c|c|}
\hline & \multicolumn{2}{|c|}{ Region1 } & \multicolumn{2}{|c|}{ Region2 } & \multicolumn{2}{|c|}{ Region 3} & \multicolumn{2}{|c|}{$\begin{array}{c}\text { Service } \\
\text { Level }\end{array}$} \\
\hline$\left(\mathrm{G}_{1}, \mathrm{G}_{2}, \mathrm{G}_{3}, \mathrm{G}_{4}, \mathrm{G}_{5}, \mathrm{G}_{6},\right)$ & $\mathrm{S}[1]$ & $\mathrm{S}[2]$ & $\mathrm{S}[3]$ & $\mathrm{S}[4]$ & $\mathrm{S}[5]$ & $\mathrm{S}[6]$ & Cost & \\
\hline$(3000,4000,6000,8000,10000,12000)$ & - & 500 & - & $\begin{array}{c}1750 \\
(1750)\end{array}$ & - & $\begin{array}{c}1750 \\
(1750)\end{array}$ & $\$ 122,000$ & $99.9 \%$ \\
\hline$(3000,4000,6000,8000,10000,22000)$ & - & 500 & - & $\begin{array}{c}1750 \\
(1750)\end{array}$ & $\begin{array}{c}1750 \\
(1750)\end{array}$ & - & $\$ 123,460$ & $99.9 \%$ \\
\hline$(3000,4000,6000,8000,20000,22000)$ & - & $(1250)$ & - & $\begin{array}{c}1250 \\
(1650)\end{array}$ & 1000 & 1750 & $\$ 126,525$ & $99.7 \%$ \\
\hline$(3000,4000,6000,18000,20000,22000)$ & - & $\begin{array}{c}1250 \\
(1250)\end{array}$ & $\begin{array}{c}250 \\
(1250)\end{array}$ & - & 1000 & 1500 & $\$ 133,610$ & $99.7 \%$ \\
\hline$(3000,4000,16000,18000,20000,22000)$ & & $(1250)$ & - & $\begin{array}{c}1250 \\
(1650)\end{array}$ & 1000 & 1750 & $\$ 136,525$ & $99.7 \%$ \\
\hline$(3000,14000,16000,18000,20000,22000)$ & 250 & - & - & $\begin{array}{c}1000 \\
(1750)\end{array}$ & 1000 & 1750 & $\$ 137,739$ & $99.7 \%$ \\
\hline$(13000,14000,16000,18000,20000,22000)$ & - & 500 & - & $\begin{array}{c}1750 \\
(1750)\end{array}$ & - & $\begin{array}{c}1750 \\
(1750)\end{array}$ & $\$ 142,000$ & $99.9 \%$ \\
\hline
\end{tabular}

As we observed, the model prioritizes suppliers for protection considering their purchasing costs. So it starts with supplier S[6] as the one with lowest purchasing cost. If its protection cost is not too high, it will protect this supplier; otherwise, it goes to the next supplier with lowest cost, supplier S[5]. This selection method continues until all suppliers have high protection costs. In all settings,two suppliers are protected, mainly suppliers S[2], and S[4], which are the two least expensive suppliers in regions 1 and 2, and two unprotected suppliers, suppliers S[5] and S[6], are also selected. Having two protected suppliers consequently increases the supply base reliability and leads to selection of unreliable and inexpensive $\mathrm{S}[5]$ and S[6] in order to make a balance between costs and risks. We also observe how costs and service level differ in different settings, when protection cost increases. It is clear (even though it is not shown here) that if the protection cost is too high, no combinations of protected and unprotected suppliers can 
lower the expected total costs compared to relying only on a multi-sourcing solution, so relying on multisourcing with unprotected suppliers will be the optimal choice of supplier selection and allocation.

\section{Discussion}

This study provides several contributions to the theory and practice of supply chain risk management that are discussed in the following sections.

\subsection{Theoretical contributions}

Chopra and Sodhi (2014) argued that managers should invest in development of capabilities to mitigate disruption risks, even though the initial investment required for developing these capabilities may not appear cost-effective at first. Our finding supports the benefits associated with investment in supply chain capabilities. We extended the existing body of literature in this area, by developing three two-stage mixed-integer programmingmodels for three basic strategies to keep emergency inventory:prepositioning inventory (warehouses), backup suppliers, and protected suppliers.In line with the literature in disruption risk management,our findings show that keeping emergency inventory is one of the main tactics that firms can use to mitigate the negative consequences of disruptions (Sheffi, 2005, Chopra and Sodhi, 2014).

We used a combination of a decision-tree analysis and a two-stage mixed-integer programming model to develop sourcing policies encompassing main suppliers, pre-positioned warehouses,backup suppliers, and protected suppliers. In each model, some of the decisions are made in the first stage, i.e., prior to disruption, and without any knowledge of outcomes of any specific scenario. First-stage decisions are the selection of the main suppliers in the supply base, the selection of warehouses to be built, the selection of backup and protected suppliers,determining the quantity of pre-positioned emergency inventory in each entity, and the selection and allocation of suppliers to satisfy emergency inventory.Second-stage decisions are those that are scenario-dependent,and comprise the contingency plans for each model,such as allocation of each supplier and quantities that flow from each member of the supply base in each scenario. Our models provide insights on supplier selection and allocation under disruption risk. To the best of our knowledge, this is the first study that examines the impact of different disruption mitigation strategies and their impact on cost and risk. By doing so, we respond to the call by Kamalahmadi and Mellat-Parast (2016a) for more analytical works on the impact of redundancies on the resiliency of a supply chain. The overall findings suggest that regardless of the mitigation strategy being implemented, a supply risk mitigation strategy reduces the effects of supply and environmental disruption and reduces the expected total cost.Thus, firms would be able to minimize the severity of disruption through implementing a supply disruption mitigation strategy.A number of sensitivity analyses are conducted on all of the important parameters of different models to provide insight into the behavior of the model and the numerical example. Also, one should note that the selection of the appropriate supply 
disruption mitigation strategy depends on a firm's overall strategy, and how the firm views the interaction between risk, cost, and reliability. Since the analysis of each of the three strategies discussed in this research study was done separately, this research study does not aim to conclude which strategy is superior.

Whilethe majority of existing studies have considered only independentsupply risk in suppliers as a source of disruption, we contribute to the SCRM literature by adding two features to the general problem: 1) environmental disruption, which makes a number of suppliers in the same location unavailable, and 2) disruption dependence, where a disrupted supplier disrupts other suppliers who depend on it. We further considered all of the combinations of failure modes, suggested contingency plans for each combination (scenario), and analyzed the cost/benefit of each strategy. Hence, we also extended Bradley (2014)'s study by examining the last two steps of his SCRM framework, evaluating and implementing risk mitigation tactics. Our results also indicate that regionalizing a supply chain (selection of suppliers and spreading other supply sources in different geographical regions) is an efficient way to reduce the risk of environmental disruptions. This result is in line with what Chopra and Sodhi (2014) discussed about the positive impacts of regionalized supply chains on risk management. Extending findings of Wagner et al. (2009), we showed that lack of attention to environmental disruptions and suppliers'independent and dependent disruptions can lead to selection of a supply base and resource allocation that is not responsive to supply chain disruptions, which makes the firm more susceptible to supply chain disruptions and increases costs.

The findings of this study provide initial insightsinto the role of supply chain complexity in supply chain designfrom arisk management perspective (Vonderembse et al., 2006; Seuring, 2009; Hammami and Frein, 2013). We realize that implementing a supply disruption mitigation strategy entails the involvement of personnel and entities in activities such as investment in warehousing systems, contracting with backup suppliers, protected supplier programs, and pre-positioning of inventory, all of which add to the complexity of the supply chain.This complexity can be a concern, especially in a Just-InSequence environment where supply base complexity (number of suppliers and their distance from the manufacturer) is considered as a major factorin the cause of disruptions (Wagner and Silveira-Camargos, 2012).In fact, Bode and Wagner (2015) showed that supply chain complexity has a positive relationship with disruption frequency. For our data set, we analyzed the effects of adding supply chain complexity on expected supply chain costs and service levels for a supply chain at risk of disruption.We found that despite an increase in supply chain complexity, when the supply base is well designed, the firm achieves a substantialreduction in expected supply chain cost and significant growth inservicelevel,compared to the less-complex general model that had nodisruption mitigation plan. This finding challenges the suggestion of the literature that supply chain complexity reduces the ability of a firm to be more responsive to 
disruptions (e.g., Craighead et al., 2007). We should realize thatsupply chain complexity is assessed as the complexity of supply base structure, but it could be assessed and evaluated in different ways, and the impact of each aspect of complexity ona firm's performance might be different. For example, manufacturers are more sensitive to supply chain delays as the product complexity increases (Inman and Blumenfeld, 2014). Thus, the impact of supply chain complexity on supply chain disruption mitigation strategies should be viewed from a contingency perspective; depending upon the nature of the complexity (e.g., product, network, or both),supply chain complexity may have a different impact on mitigating disruptions.

\subsection{Managerial implications}

Our models provide significant insights and important implications for operations and supply chain managers to properly incorporate risk management in their supply chain design.

First,adding redundancy to the supply chainis a strategy that requires managers to invest in disruption mitigation programs before any disruption occurs.Due to the very low likelihood of disruptions, managers may not be inclined to value such investments (Chopra and Sodhi, 2014).In fact, keeping excess inventory as one of the supply mitigation strategies challenges some of the current thinking and management practices such as lean and JIT,in which limited or no inventory is promoted (Ericsson and Dahlén, 1997; Shah and Ward, 2007; Son and Orchard, 2013). Implementing lean management practices that underline operating under low inventory levels while reducing the complexity of the supply chain may lead to more visibility and reducing potential supply disruptions (e.g., Marley et al., 2014). However, a comprehensive supply chain risk management disruption mitigation strategy is not limited to just minimizing supply disruptions; it should encompass other sources of risksuch as the environmentas well as the impact of disruptions on interdependent suppliers.From the lean management perspective, excess inventory is not recommended, but the supply chain risk management view promotes availability of excess capacity in order to respond to disruptions. Thus, it is important for supply chain managers to fully understand the pros and cons of implementing any management practices with respect to their implications for supply chain risk, and the extent to which these management practices strengthen (or weaken) the firm's capability to respond to disruptions.

Second,the results highlighted the significant impact of two phenomena on supply chain performance: 1) environmental disruptions (Trkman and McCormack, 2009; Olson and Swenseth, 2014);and 2) supplier dependence (Babich et al., 2007; Wagner et al., 2009).In our study, we examined the extent to which a regionalized supply chain along with redundant entities can mitigate supply chain disruption due to environmental and/or interlinked supplier disruptions.This provided a more nuanced explanation of the effectiveness of the redundancy strategies in improving the responsiveness of the firm to dependent and independent supplier and environmental disruptions. In our sensitivity analyses, we 
carefully examined how assigning different values for disruption probabilities and dependencies can affect the final result of each model. We reviewed how the selection and allocation of warehouses, backup suppliers, and protected suppliers is affected when very reliable/unreliable suppliers, very reliable/unreliable regions, and very dependent/independent suppliers exist. Our result suggests that operations and supply chain managers may need to work with a different set of supplierswhen disruptions happen; the selection and resource allocation of suppliers is quite different when disruption dependence and environmental riskare incorporated into the model. Thus, failing to addressall types of disruptions and suppliers' interdependence in the design of a supply chain and the development of disruption mitigation strategies, which has been generally overlooked in prior studies in supply chain risk management,could have significant negative consequences on firm performance. The importance of environmental risk should be stressed more by managers, since the firm has less control over environmental risk compared to other sources of risk in the supply chain. Regionalizing a supply chain is a strategy suggested by Chopra and Sodhi (2014) as a way to mitigate the consequences of environmental disruptions. For our data set, we examined the impact of the regionalizing strategy by providing a set of heterogeneous suppliers that also share some commonalities with the other suppliers in their proximity. Our results supported the diversification of a supply chain by allocating less demand to a greater number of suppliers and having multiple suppliers from multiple regions, both of which can help firms reduce the impact of environmental and supplier disruptions.

Third, our study provides insights into the decisions regarding supplier selection and demand allocation under different scenarios, considering three types of redundancies. Based on the General Model with only multi-sourcing strategy,our study shows that operations and supply chain managerswho are not interested in disruption mitigation strategies should select the most reliable suppliers (though expensive) from the most reliable region, which minimizes the likelihood of disruptions and their negative consequences.Ifredundancy in the form of inventory is desirable, since inventory is kept in the warehouses and responsiveness of firms has increased, the firm should put more weight on cost factors when choosing suppliers. The manufacturer should spread the demand across entities in different regions to minimize environmental disruptions and disruption dependence impact on the supply chain. With respect to backup suppliers, the findings suggest that the manufacturer should put more weight on cost factors when choosing primary suppliers and more weight on reliability factors when choosing backup suppliers. This way, there would be a balance between costs and reliability, which increases responsiveness of the firms while keeping costs low. With respect to the supplier protection model, a manufacturer should prioritize suppliers for protection with respect to their cost factor. Although the protection costs of a less reliable less expensive supplier might be more than a more reliable one, the benefits that the manufacturer achieves would outweigh that protection cost, if disruptions hit the supply 
chain. Out sensitivity analyses of fixed disruption management capability development costs show that these capability development investments are only justified if the expected total costs of the supply chain, summed over all of the scenarios that may happen due to the different types of independent and dependent disruptions, with new entities would be less that the expected total costs of the same supply chain with no inventory, backup, or protected suppliers. Therefore a necessary analysis and estimation of capability development fixed costs is required before making any decision regarding these strategies.

\subsection{Limitations and future research}

Our study and the experiment design have several limitations. Although our stochastic model can capture all different scenarios that may happen as a result of supplier and regional disruptions, deterministic values for parameters may not able to fully capture the dynamic nature of supply chains. We believe usingdata from multiple firms would validate the findings of this study. Furthermore, we did not consider a time horizon in any of our strategies. The models were assumed to be performed in a one-cycle demand period, and no backlog was allowed.Incorporating time-dependent demand to the models and allowing a portion of unsatisfied demand to be delivered in future periods would be an interesting research topic. Future studies should also examine the impact of multiple products from multiple suppliers to examine whether the findings could be generalized to a new set of factors and assumptions.

Another interesting direction for future studies would be to investigate other aspects of supply chain complexity and its relationship with firm performance under supplier and environmental risk. For example, according to Whitney et al. (2014), using temporary suppliers in case of disruptions is more feasible when the disrupted items are less specific and are readily available from alternate sources, which means a strategy like backup suppliers loses valueand feasibility when product or process complexity increases. Furthermore, future studies can address supplier selection and resource allocation beyond the two-echelon supply chains.

In this study of our data set, we aimed to show how adding redundancy to the supply chain in different forms can provide opportunities to both minimize the impact of disruptions and reduce expected supply chain costs. This study did not attempt to compare the different SCRM strategies in the supply chain; future studies can integrate all of the aforementioned strategies into a particular model to investigate the superiority of each one in different circumstances. In addition, while we were able to utilize the data from a manufacturing firm that was used in prior studies (Ruiz-Torres et al., 2013; Kamalahmadi and Mellat-Parast, 2015), future studies can examine the validity of our results using data from multiple cases in order to improve the validity and generalizability of the results.

\section{Conclusion}

This paper examinedthe impact of adding three types of redundancies to a supply chain: prepositioning inventory, backup suppliers, and protected suppliers. To evaluate the impact of supply and 
environmental risks and suppliers' disruption dependence, a two-stage mixed-integer model was developed to determine the best sourcing and procurement strategy for supplier selection and demand allocation, with the objective of minimizing expected total cost. We further incorporated each redundancy into our model and examined the impact of each mitigation strategy in sourcing and procurement decisions. Contingency plans weredeveloped for each strategy in order to mitigate the severity of both supply and environmental disruptions. The proposed models enhance our understanding of supply chain risk management through assessment ofthe impact of different disruption management strategies in sourcing and procurement decisions.

Acknowledgement: This research is based upon work supported by the National Science Foundation (NSF) under grant number 123887 (Research Initiation Award: Understanding Risks and Disruptions in Supply Chains and their Effect on Firm and Supply Chain Performance).

\section{REFERENCES}

Azadegan, A., Patel, P. C., and Parida, V. (2013) Operational slack and venture survival,Production and Operation Management, 22(1), pp. 1-18.

Babich, V., Ritchken, P. H., Burnetas, A. N. (2007) Competition and diversification effects in supply chains with supplier default risk, Manufacturing and Service Operations Management, 9(2), pp. 123-146.

Berger, P. D., Gerstenfeld, A., and Zeng, A. Z. (2004) How many suppliers are best? A decision-analysis approach,Omega: International Journal of Management Sciences, 32(1), pp. 9-15.

Berger, P. D., and Zeng, A. Z. (2006) Single versus multiple sourcing in the presence of risks, Journal of the Operational Research Society, 57(3), pp. 250-261.

Birge, J.R., and Louveaux, F. (1997) Introduction to stochastic programming. Springer-Verlag, New York.

Bode, C., and Wagner, S. M. (2015) Structural drivers of upstream supply chain complexity and the frequency of supply chain disruptions, Journal of Operations Management, 36, pp. 215-228.

Bradley, J. R. (2014) An improved method for managing catastrophic supply chain disruptions, Business Horizons, 57(4), pp. 483-495.

Chappell, L., and Sedgwick, D. (2009) Toyota stockpiles parts as precaution, Automotive News, April, 27.

Che, Z. H., and Wang, H.S. (2008) Supplier selection and supply quantity allocation of common and non-common parts with multiple criteria under multiple products, Computer and Industrial Engineering, 55, pp. 110-133.

Chen, J., Zhao, X., and Zhao, Y. (2012) A periodic-review inventory system with a capacitated backup supplier for mitigating supply disruptions,European Journal of Operational Research, 219(2), pp. 312323. 
Chen, P. S., and Wu, M. T.(2013)A modified failure mode and effects analysis method for supplier selection problems in the supply chain risk environment: A case study, Computers \& Industrial Engineering,66(4), pp. 634-642.

Chopra, S., and Sodhi, M. S. (2014) Reducing the risk of supply chain disruptions,MIT Sloan Management Review, 55(3), pp. 72-80.

Craighead, C., Blackhurst, J., Rungtsunatham, M. J., and Handfield, R. (2007) The severity of supply chain disruptions: Design characteristics and mitigation capabilities,Decision Sciences, 38(1), pp. 131156.

Ericsson, J., and Dahlén, P. (1997) A conceptual model for disruption causes: A personnel and organization perspective, International Journal of Production Economics, 52(1/2), pp. 47-53.

Fuller, T. (2012) Floodwaters are gone, but supply chain issues linger, The New York Times, January, 21.

Ghadge, A., Dani, S., and Kalawsky, R. (2013) Supply chain risk management: Present and future scope, International Journal of Logistics Management, 23(3), pp. 313-339.

Greising, D., and Johnsson, J. (2007) Behind Boeing’s 787 delays, Chicago Tribune, December, 08.

Greenhouse, S. (2013) Major retailers join Bangladesh safety plan, New York Times, May 13.

Guericke, S., Koberstein, A., Schwartz, F., andVoß, S. (2012) A stochastic model for the implementation of postponement strategies in global distribution networks, Decision Support Systems, 53(2), pp. 294-305.

Hammami, R., and Frein, Y. (2013) An optimisation model for the design of global multi-echelon supply chains under lead time constraints, International Journal of Production Research, 51(9), pp. 2760-2775.

Hedricks, K. B., Singhal, V. R., and Zhang, R. (2009) The effect of operational slack, diversification, and vertical relatedness on the stock market reaction to supply chain disruptions,Journal of Operation Management, 27(3), pp. 233-246.

Inman, R. R., and Blumenfeld, D. E. (2014) Product complexity and supply chain design, International Journal of Production Research, 52(7), pp. 1956-1969.

Irvine, F. (2003) Long term trends in US inventory to sales ratios, International Journal of Production Economics, Proceedings of the Eleventh International Symposium on Inventories, 81-82, pp. 27-39.

Kamalahmadi, M., and Mellat-Parast, M. M. (2016a) A review of the literature on the principles of enterprise and supply chain resilience: Major findings and directions for future research, International Journal of Production Economics, 171(1), pp. 116-133.

Kamalahmadi, M., and Mellat-Parast, M. M. (2016b) Developing a resilient supply chain through supplier flexibility and reliability assessment. International Journal of Production Research,54(1), pp. 302-321.

Li, Y. P., Huang, G. H., Nie, X. H., andNie, S. L. (2008) A two-stage fuzzy robust integer programming approach for capacity planning of environmental management systems, European Journal of Operational Research,189(2), pp. 399-420. 
Marley, K. A., Ward, P. T., and Hill, J. A. (2014) Mitigating supply chain disruptions - a normal accident perspective, Supply Chain Management, 19(2), pp. 142-152.

Meena, P. L., Sarmah, S. P., and Sarkar, A. (2011) Sourcing decisions under risks of catastrophic event disruptions, Transportation Research Part E, 47(6), pp. 1058-1074.

Meena, P. L. and Sarmah, S. P. (2013) Multiple sourcing under supplier failure risk and quantity discount: A genetic algorithm approach, Transportation Research Part E, 50(1), pp. 84-97.

Mendoza, A., and Ventura, J. (2012) Analytical models for supplier selection and order quantity allocation, Applied Mathematical Modeling, 36(8), pp. 3826-3835.

Obermaier, R. (2012) German inventory to sales ratios 1971-2005-An empirical analysis of business practice, International Journal of Production Economics,135(2), pp. 964-976.

Olson, D. L., and Swenseth, S. R. (2014) Trade-offs in supply chain system risk mitigation, Systems Research \& Behavioral Science, 31(4), pp. 565-579.

Paul, S. K., Sarker, R., and Essam, D. (2015) A disruption recovery plan in a three-stage productioninventory system, Computers \& Operations Research, 57(C), pp. 60-72.

Qin, X., Liu, X., and Tang, L. (2013) A two-stage stochastic mixed-integer program for the capacitated logistics fortification planning under accidental disruptions,Computers \& Industrial Engineering, 65(4), pp. 614-623.

Rafiei, M., Mohammadi, M., and Torabi, S. A. (2013) Reliable multi period multi product supply chain design with facility disruption, Decision Science Letters,2(2), pp. 81-94.

Rawls, C. G., andTurnquist, M. A. (2010) Pre-positioning of emergency supplies for disaster response,Transportation Research Part B: Methodological, 44(4), pp. 521-534.

Roberta Pereira, C., Christopher, M., and Lago Da Silva, A. (2014) Achieving supply chain resilience: The role of procurement, Supply Chain Management: An International Journal,19(5/6), pp. 626-642.

Ruiz-Torres, A. J., and Mahmoodi, F. (2007) The optimal number of suppliers considering the costs of individual supplier failures. Omega: International Journal of Management Science, 35(1), pp. 104-115.

Ruiz-Torres, A. J., Mahmoodi, F., and Zeng, A. Z. (2013) Supplier selection model with contingency planning for supplier failures,Computers \& Industrial Engineering, 66(2), pp. 374-382.

Sarkar, A., and Mohapatra, P. K. J. (2009) Determining the optimal size of supply base with the consideration of risks of supply disruptions, International Journal of Production Economics, 119(1), pp. 122-135.

Sawik, T. (2013) Selection of resilient supply portfolio under disruption risks, Omega: International Journal of Management Science, 41(2), pp. 259-269.

Sawik, T. (2014) Optimization of cost and service level in the presence of supply chain disruption risks: Single vs. multiple sourcing, Computers \& Operations Research, 51(1), pp. 11-20. 
Seuring, S. (2009) The product-relationship-matrix as framework for strategic supply chain design based on operations theory, International Journal of Production Economics, 120(1), pp. 221-232.

Shah, R., and Ward, P. T. (2007) Defining and developing measures of lean production, Journal of Operations Management, 25(4), pp. 785-805.

Sheffi, Y. (2005) Preparing for the big one, Manufacturing Engineer, 84(5), pp. 12-15.

Sodhi, M. S., and Lee, S. (2007) An analysis of sources of risk in the consumer electronics industry, Journal of the Operational Research Society, 58(11), pp. 1430-1439.

Sodhi, M. S., Son, B. G., and Tang, C. S. (2012) Researchers' perspectives on supply chain risk management, Production and Operation Management, 21(1), pp. 1-13.

Son, J. Y., and Orchard, R. K. (2013) Effectiveness of policies for mitigating supply disruptions, International Journal of Physical Distribution \& Logistics Management, 43(8), pp. 684-706.

Tomlin, B. (2006) On the value of mitigation and contingency strategies for managing supply-chain disruption risks, Management Science, 52(5), pp. 639-657.

Torabi, S. A., Baghersad, M., and Mansouri, S. A. (2015) Resilient supplier selection and order allocation under operational and disruption risks, Transportation Research Part E, 79, pp. 22-48.

Trkman, P., and McCormack, K. (2009) Supply chain risk in turbulent environments-A conceptual model for managing supply chain network risk, International Journal of Production Economics, 119(2), pp. 247-258.

Vonderembse, M. A., Uppal, M., Huang, S. H., and Dismukes, J. P. (2006) Designing supply chains: towards theory development, International Journal of Production Economics, 100(2), pp. 223-238.

Wagner, S. M., Bode, C., and Koziol, P. (2009) Supplier default dependencies: Empirical evidence from the automotive industry, European Journal of Operational Research, 199(1), pp. 150-161.

Wieland, A.,and Wallenburg, C. M. (2012) Dealing with supply chain risks: Linking risk management practices and strategies to performance,International Journal of Physical Distribution \& Logistics Management, 42(10), pp. 887-905.

Wilson, M. C. (2007) The impact of transportation disruptions on supply chain performance, Transportation Research Part E: Logistics and Transportation Review, 43(4), pp. 295-320.

Wagner, S.M., and Silveira-Camargos, V. (2012) Managing risks in just-in-sequence supply networks: Exploratory evidence from automakers, IEEE Transactions on Engineering Management, 59(1), pp. 5264.

$\mathrm{Xu}$, N., and Nozick, L. (2009) Modeling supplier selection and the use of option contracts for global supply chain design,Computers \& Operations Research, 36(10), pp. 2786-2800.

Zsidisin, G. A., and Wagner, S. M. (2010) Do perceptions become reality? The moderating role of supply risk resiliency on disruption occurrence, Journal of Business Logistics,31(2), pp. 1-20. 